ISEP XIV

Correspondence

Alastair G. B. Simpson

asimpso2@dal.ca

\section{Cytoskeletal organization, phylogenetic affinities and systematics in the contentious taxon Excavata (Eukaryota)}

\author{
Alastair G. B. Simpson \\ Canadian Institute for Advanced Research, Program in Evolutionary Biology, Department of \\ Biology, Dalhousie University, Halifax, NS, Canada B3H 4J1
}

\begin{abstract}
An overview of the controversial proposal for the major eukaryote taxon 'Excavata' is presented. Excavata is predicted to include at least ten distinct groups: jakobids, Malawimonas, Trimastix, Carpediemonas, retortamonads, diplomonads, Heterolobosea, oxymonads, parabasalids and Euglenozoa. These 'excavates' have broadly similar flagellar apparatus organizations, for which a 'universal' terminology is provided. Most, but not all, of these organisms share a distinctive suspension-feeding groove, as well as some or all of a set of seven other proposed cytoskeletal apomorphies. Cladistic analyses of morphological data do not resolve high-level relationships within Excavata. Excavate-rich molecular phylogenies recover some robust clades, but do not support or strongly refute the monophyly of Excavata. A partial classification for excavates is presented, with phylogenetic diagnoses for Excavata and for two novel taxon names, Fornicata (Carpediemonas, retortamonads, diplomonads) and Preaxostyla (Trimastix, oxymonads).
\end{abstract}

\section{Introduction}

The last 15 years have seen unprecedented advances in our understanding of the relationships among eukaryotes. Some major, largely unexpected groupings have emerged, primarily through the application (and, sometimes, intelligently selective interpretation) of molecular phylogenetics. However, molecular phylogenetic approaches have limitations, which are nowhere revealed more starkly than in the stories of many of the supposedly 'deep-branching' eukaryotes, such as diplomonads (e.g. Giardia), parabasalids (e.g. Trichomonas), retortamonads, oxymonads, Heterolobosea and Euglenozoa. Earlier molecular phylogenetic evidence that these organisms represented a series of basal branches in the eukaryotic tree has been largely discredited by later analyses (Embley \& Hirt, 1998; Philippe \& Adoutte, 1998; Philippe et al., 2000). However, positive indications of their true evolutionary positions have remained elusive, despite considerable efforts in gene, and even genome, sequencing.

Nonetheless, it has recently been proposed that these problematic taxa form the bulk of a novel major clade of eukaryotes, which has recently acquired the formal moniker Excavata (Cavalier-Smith, 2002). The hypothesis is controversial - it draws support primarily from morphological

This paper was presented at the XIVth meeting of the International Society for Evolutionary Protistology in Vancouver, Canada, 19-24 June 2002.

Abbreviations: R1-R4, roots 1-4; SSU, small-subunit; TBR, tree bisection-reconnection. data (O'Kelly, 1993; Simpson \& Patterson, 1999) rather than from molecular phylogenies, which generally place organisms with very similar appearances in widely separated locations in the tree of eukaryotes (Simpson et al., 2002c). Conversely, some intriguing and robust lower-level relationships within Excavata have emerged from molecular phylogenetic studies, rather than from morphological comparisons (Dacks et al., 2001; Silberman et al., 2002; Simpson et al., 2002c). This paper reviews the diversity, morphology and evolutionary relationships of the relevant organisms, including: (i) the origins of Excavata as a phylogenetic concept; (ii) the cellular ultrastructure of the organisms involved, highlighting potential apomorphies and providing a standardized terminology; (iii) the relationships 'within' Excavata, as indicated by both morphological and molecular data; and (iv) phylogenetic definitions for the taxon and some clades that are predicted to lie within it.

\section{Origins: Excavata, excavate taxa and the excavate hypothesis \\ Excavate taxa}

Some heterotrophic flagellates employ a longitudinal groove to collect suspended food particles from a current generated by the beating of one or more posteriorly directed flagella. Such organisms were recently characterized as 'excavate' (Patterson, 1999; Simpson \& Patterson, 1999). Well-accepted monophyletic groups including such organisms are designated 'excavate taxa'; thus, some (potentially most) members of an excavate taxon can lack an excavate feeding groove. There are currently seven excavate taxa: 
Jakobida (core jakobids), Malawimonas, Trimastix, Carpediemonas, Retortamonadida, Diplomonadida and Heterolobosea.

The first four of these seven groups are composed exclusively of free-living, heterotrophic flagellates with conspicuous feeding grooves. These organisms have only been characterized within the last 15 years. The taxon Jakobida contains mitochondriate, biflagellate cells (Fig. 1a), including the free-swimming Jakoba (Patterson, 1990) and the sessile, loricate Histiona and Reclinomonas (Mylnikov, 1989; Flavin \& Nerad, 1993). Stenocodon and Stomatochone are probably related closely to Reclinomonas and Histiona (Flavin \& Nerad, 1993; Patterson et al., 2000b). O'Kelly (1993) recognized that Jakoba, Reclinomonas and Histiona were morphologically similar (see also Flavin \& Nerad, 1993) and called them 'jakobid flagellates', together with an unnamed, free-swimming, groove-bearing flagellate that was later described as Malawimonas jakobiformis (O'Kelly \& Nerad, 1999). Further studies cast doubt as to whether Malawimonas was related particularly closely to other 'jakobid flagellates' (O’Kelly \& Nerad, 1999; Simpson \& Patterson, 1999) and the inclusiveness of this term became confused. For expediency, Jakoba, Reclinomonas and Histiona were referred to as 'core jakobids' (Simpson \& Patterson, 1999, 2001). Hereafter, the taxon 'Jakobida' and the term 'jakobids' are held to be synonymous with 'core jakobids', i.e. Malawimonas is not a jakobid and is considered to be a separate taxon (Archibald et al., 2002; Cavalier-Smith, 2002). Trimastix and Carpediemonas are free-swimming cells that are usually encountered in oxygen-poor environments (Bernard et al., 2000). Both lack mitochondria, but possess double-membrane-bounded organelles that may be
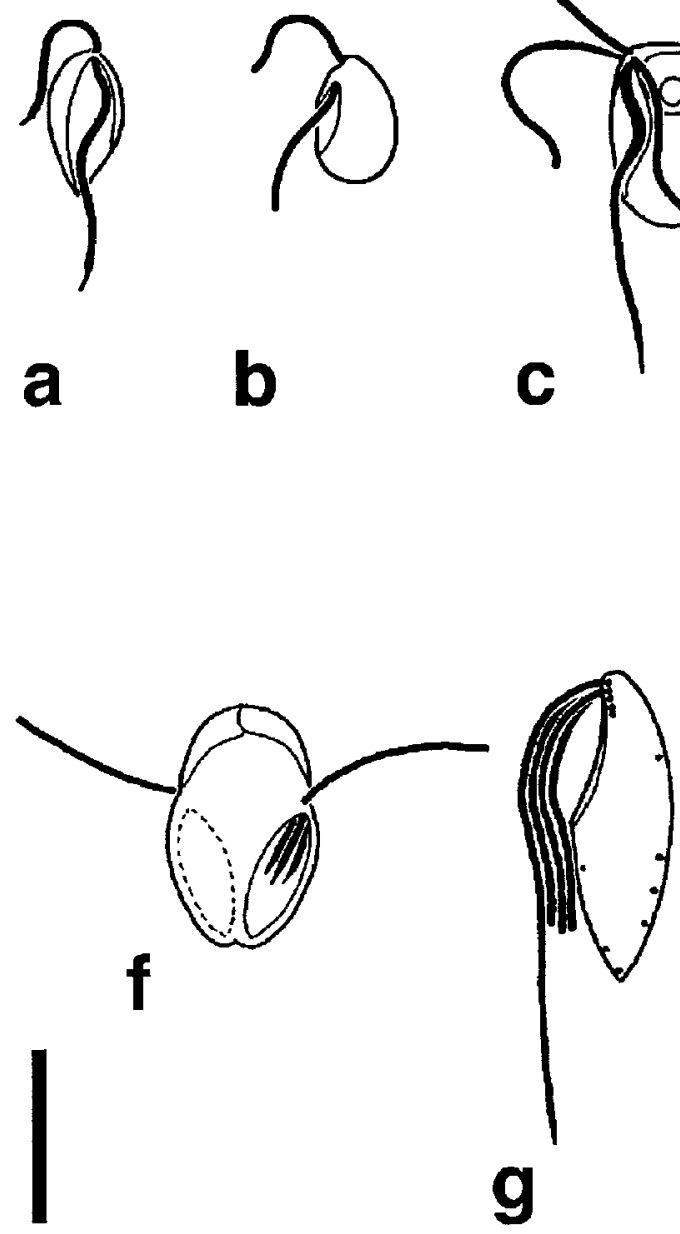

g

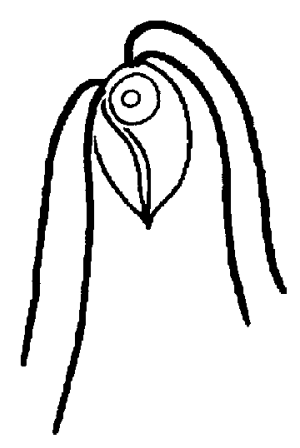

h
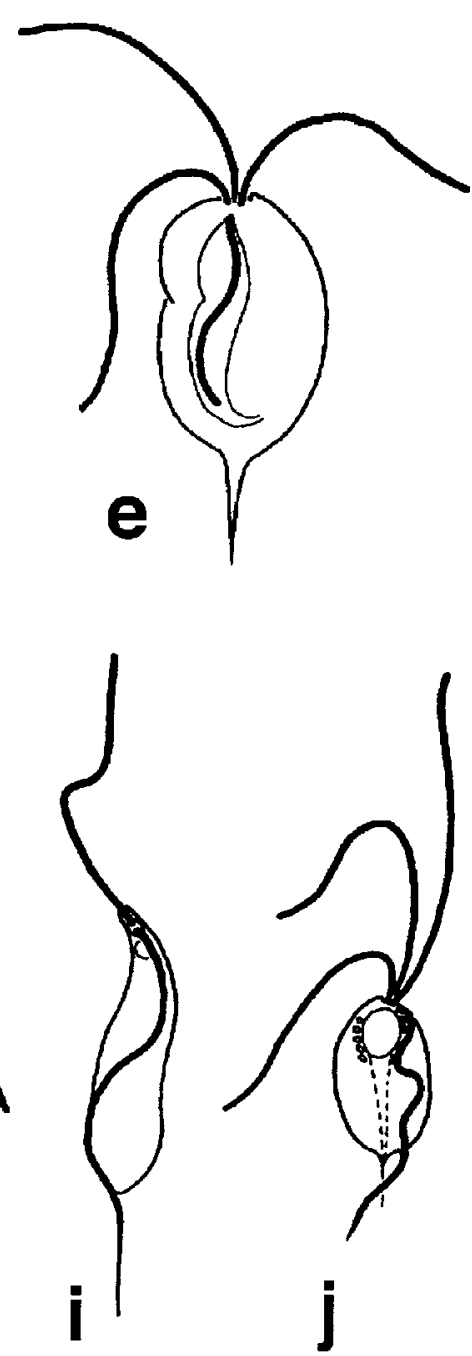

Fig. 1. Light microscopic appearance of the ten groups of Excavata. (a) Jakobid: Jakoba incarcerata; (b) Malawimonas: Malawimonas jakobiformis; (c) Trimastix: Trimastix pyriformis; (d) Carpediemonas: Carpediemonas membranifera; (e) retortamonad: Chilomastix cuspidata; $(\mathrm{f})$ diplomonad: Trepomonas agilis; (g) heteroloboseid: Percolomonas descissus; (h) oxymonad: Monocercomonoides hausmanni; (i) euglenozoon: Dimastigella trypaniformis; (j) parabasalid: Pseudotrichomonas keilini. Parts a, c-g, i and j are after Bernard et al. (2000); parts b and h are after Simpson et al. (2002b). Bar, $10 \mu \mathrm{m}$. 
homologous (Brugerolle \& Patterson, 1997; O'Kelly et al., 1999; Simpson \& Patterson, 1999; Simpson et al., 2000). Trimastix has four flagella, whereas Carpediemonas is biflagellate, but has three basal bodies (Simpson \& Patterson, 1999). Jakobids, Malawimonas, Trimastix, Carpediemonas and retortamonads (see below) are informally referred to as 'typical' excavates, due to their similar cytoskeletal organization.

Retortamonads and diplomonads are the best known of the excavate taxa. These heterotrophic flagellates lack classical mitochondria and typically inhabit oxygen-poor environments, such as sediments and the intestinal tracts of vertebrates (Kulda \& Nohynková, 1978; Mylnikov, 1991; Fenchel \& Finlay, 1995; Bernard et al., 2000). Retortamonads have four basal bodies, with either two (Retortamonas) or four (Chilomastix) emergent flagella and a conspicuous ventral groove (Brugerolle, 1991a; Brugerolle \& Müller, 2000). Most diplomonads are doubled cells with two nuclei, two kinetids (most have two sets of four flagella) and duplicate cytoskeletons (Brugerolle, 1991a; Brugerolle \& Müller, 2000). The most familiar diplomonad, the intestinal parasite Giardia, lacks feeding grooves. However, Trepomonas spp. and (arguably) Enteromonas have feeding grooves that operate in conjunction with the posterior flagella (Brugerolle, 1975a; Eyden \& Vickerman, 1975). Many workers consider diplomonads and retortamonads together as a clade or as a phenetically united grade (e.g. Cavalier-Smith, 1987, 1993, 1999; Lipscomb, 1989; Siddall et al., 1992), but others, conservatively, consider them separately (e.g. Patterson, 1994, 1999).

Heterolobosea (=Tetramitea sensu Cavalier-Smith) was united as a taxon by Page \& Blanton (1985), with the key organism Percolomonas cosmopolitus included by Fenchel \& Patterson (1986). Heterolobosea are primarily amoebae or (acrasid) slime moulds, but many have alternative flagellate forms with two or four flagella and some (Lyromonas, Percolomonas) may exist only as flagellates (Patterson et al., 2000a). Flagellates of Percolomonas, Lyromonas, Psalteriomonas and arguably some others (e.g. Tetramitus, Paratetramitus) have a broad ventral (or anterior) groove (Patterson et al., 2000a). This is used for suspension-feeding, at least in Percolomonas (Fenchel \& Patterson, 1986).

This list of excavate taxa is probably not exhaustive. For example, Ruinen (1938) described two free-living, groovebearing flagellates with three flagella, Triflagellum diaphanum and Triflagellum hardyi. The groove of Triflagellum diaphanum is similar to those of Trimastix and Carpediemonas and is associated with a single posterior flagellum. Bernard et al. (2000) documented a small flagellate 'protist $\beta$ ' with a ventral groove that contained a posterior flagellum. Feeding data are not available for these organisms, but suspension-feeding is plausible in each case. They are not immediately assignable to any established taxon, but neither electron microscopical, nor molecular, data are yet available.

\section{Potentially related organisms}

Several other groups of organisms lack an excavate feeding groove, but other evidence (other discrete characters and/or molecular phylogenies) suggests that they share a common ancestry with some or all excavate taxa.

Oxymonads are gut endobionts of various animals, especially termites (Brugerolle \& Müller, 2000; Brugerolle \& Lee, 2000a). They lack a feeding groove, although a tiny channel with no apparent feeding function is present in some examples (Simpson et al., 2002b). Oxymonads have been classified or placed phylogenetically with diplomonads and retortamonads (sometimes together with parabasalids see below) (Brugerolle \& Taylor, 1977; Cavalier-Smith, 1981, 1998; Corliss, 1994) and occasionally with heteroloboseids (Cavalier-Smith, 1999, 2000). However, recent molecular and morphological data suggest a close relationship with Trimastix (Dacks et al., 2001; Simpson et al., 2002b).

Almost all parabasalids are parasites or commensals of animals (Brugerolle \& Müller, 2000). They are usually tetraflagellate, pentaflagellate or multiflagellate, have hydrogenosomes and lack a feeding groove (Brugerolle \& Müller, 2000). Many molecular phylogenies place parabasalids in a clade with diplomonads (Embley \& Hirt, 1998; Dacks \& Roger, 1999; Baldauf et al., 2000).

Euglenozoans are unicellular (rarely colonial) flagellates. Best known are the photosynthetic 'green euglenids' (mostly uniflagellate) and the uniflagellate, parasitic trypanosomatids, but the bulk of euglenozoan diversity consists of free-living biflagellate phagotrophs (Simpson, 1997). Euglenozoans feed by using a tubular ingestion apparatus rather than a ventral groove. Most free-living taxa are raptorial feeders. The few suspension-feeders (e.g. Bodo saltans) use their anterior flagellum to generate the feeding current. The taxon Euglenozoa is usually considered to be related to Heterolobosea, based on some ultrastructural features (Patterson, 1988) and some molecular phylogenies (Baldauf et al., 2000; Edgcomb et al., 2001).

\section{Unrelated groove-bearing cells}

Some other moderately well-known taxa have conspicuous ventral grooves, but do not perform suspension-feeding. Collodictyonids (diphylleiids) are free-living predatory flagellates with two or four anteriorly directed flagella that insert at the anterior end of a broad ventral groove (Brugerolle et al., 2002). This groove is used to ingest prey, but feeding is raptorial. It has been proposed that this groove is homologous to the suspension-feeding groove of excavate taxa (Cavalier-Smith, 2002); however, there is no strong case that any other distinctive morphological feature of excavate taxa is shared by collodictyonids (see below), nor is there a consistent association between collodictyonids and any of the excavate taxa in molecular phylogenies. 
Colponema is a free-swimming flagellate with a prominent ventral groove that is associated with a posterior flagellum, but it is also a raptorial predator that ingests large eukaryotic prey (Mignot \& Brugerolle, 1975). Colponema has peripheral alveolae (Mignot \& Brugerolle, 1975) and is usually considered to be an alveolate (Patterson \& Zölffel, 1991; Cavalier-Smith, 1993; Leander \& Keeling, 2003); it is therefore not discussed further here.

\section{Original evolutionary concepts}

The history of the phylogenetic and systematic treatment of various excavate taxa is entwined with the archezoa hypothesis (Roger, 1999). This hypothesis held that some mitochondrion-lacking eukaryotes, including diplomonads and retortamonads, were the deepest extant branches of the eukaryotic tree, having diverged before the unique acquisition of mitochondria by eukaryotes (Cavalier-Smith, 1983). The archezoa hypothesis became widely accepted by the early 1990s, primarily because small-subunit rRNA gene (SSU-rRNA) phylogenies generally placed various amitochondriate taxa, including diplomonads, at the base of the eukaryotic tree (Sogin, 1989). Similarities between diplomonads and/or retortamonads and any particular mitochondriate taxa were therefore interpreted initially either as plesiomorphies (retained ancestral features) for all eukaryotes or, implicitly, as evolutionary convergences.

Aside from proposals to unite diplomonads and retortamonads in various ways, the first detailed suggestions for evolutionary links between excavate taxa involved Heterolobosea and retortamonads/diplomonads. In broad-scale comparisons, Sleigh (1989) noted that some heteroloboseids and retortamonads (and, to a lesser extent, some diplomonads) had broadly similar flagellar apparatuses, including similar coarsest-level groove architecture. Meanwhile, early SSU-rRNA trees placed Heterolobosea as one of the deepest mitochondriate branches (Sogin, 1989; Hinkle \& Sogin, 1993). Inspired by these data and the shared lack of obvious dictyosomes in heteroloboseids, diplomonads and retortamonads, Cavalier-Smith (1991, 1992a, b) argued that heteroloboseids were the ancestral mitochondriate eukaryotes, being immediately descended from a primitively amitochondriate retortamonad or retortamonad-like organism. In these proposals, the possibility of homology among the feeding grooves was not considered in depth and, implicitly, the grooves of jakobids were presumed to have evolved independently.

O'Kelly (1993) examined jakobids and Malawimonas together for the first time and noted several structural similarities with retortamonads: details of the groove cytoskeleton, flagellar elaboration, basal body arrangement and organization of division. O'Kelly formed a phylogenetic hypothesis similar to Cavalier-Smith's, but placed jakobids plus Malawimonas as the ancestral mitochondriate eukaryotes, with heteroloboseids as later descendants (O'Kelly, 1993). This scheme held that the feeding grooves of heteroloboseids, jakobids, Malawimonas and retortamonads (and implicitly diplomonads) were all homologous structures. More detailed studies of the jakobid Reclinomonas (O'Kelly, 1997) and Malawimonas (O'Kelly \& Nerad, 1999) confirmed an ultrastructural organization similar to those of retortamonads and heteroloboseids. Although first reported to have a 'novel' organization (Brugerolle \& Patterson, 1997), Trimastix is also similar structurally to jakobids and Malawimonas (O'Kelly et al., 1999; Simpson \& Patterson, 1999; Simpson et al., 2000), as is Carpediemonas (Simpson \& Patterson, 1999).

\section{The excavate hypothesis}

In the last half of the 1990s, the primitively amitochondriate status of diplomonads was challenged by the discovery of putative mitochondrial isoforms of cpn60, IscS and perhaps HSP70 (Roger et al., 1998; Horner \& Embley, 2001; Morrison et al., 2001; Tachezy et al., 2001). Recently, tiny relict mitochondrial organelles have been identified in Giardia (Tovar et al., 2003). Furthermore, it has become clear that the basal portions of eukaryotic molecular phylogenies may be structured by analysis artefacts, rather than by true historical signal (Philippe \& Adoutte, 1998; Hirt et al., 1999; Stiller \& Hall, 1999; Philippe et al., 2000). The deeply diverged position of diplomonads is now seriously in question.

Accommodating the possibility that diplomonads and retortamonads are not deeply branching eukaryotes, Simpson \& Patterson (1999) recast the evolutionary scheme of O'Kelly (1993) as a more general homology argument, the 'excavate hypothesis'. This contends simply that the feeding grooves of the various excavate taxa are all homologous. The excavate hypothesis implies that the excavate taxa are a monophyletic or, significantly, a paraphyletic assemblage. The latter would imply that some of the descendants of the first organism with an excavate feeding groove subsequently lost this groove (in addition to organisms that lie within recognized excavate taxa and lack feeding grooves, e.g. Giardia). In O'Kelly's original scheme, for example, all mitochondriate eukaryotes are descended from the first organisms with excavate feeding grooves (O'Kelly, 1993).

\section{From 'excavate taxa' to 'Excavata'}

Bearing in mind this possibility that the assemblage of 'excavate taxa' could be paraphyletic, a clade can be envisaged that comprises the first organism with an excavate feeding groove and all its descendants. If the excavate hypothesis is correct, this clade exists and would include all excavate taxa, plus any other groups descended from within them that have lost the feeding groove. This putative clade is referred to here as Excavata and its members as 'excavates'. Current evidence (see below) indicates that oxymonads, parabasalids and Euglenozoa may well belong to Excavata, in addition to the excavate taxa. At present, there is no particular evidence that places any other wellcharacterized eukaryotes within Excavata. 
Recently, Cavalier-Smith (2002) created the taxon Excavata as an infrakingdom. This taxon includes all excavate taxa plus Euglenozoa, parabasalids, oxymonads and collodictyonids (Diphylleiida). Cavalier-Smith's taxon Excavata is conceptually somewhat different from the clade envisaged above, being diagnosed without reference to the feeding groove, but its composition is identical to that predicted here, barring collodictyonids.

\section{Morphological evidence: the excavate cytoskeleton}

The excavate feeding groove is a single morphological character that is proposed, under the excavate hypothesis, to be homologous across all excavate taxa. It is clear, however, that striking morphological features can evolve convergently in distantly related protists (witness the polyphyly of traditional assemblages such as 'amoebae', 'sporozoa', 'heliozoa', etc.). It is therefore important to determine whether other morphological characters appear to be widespread in excavates and distinctive for the group. In the absence of a reliable phylogenetic tree, a suite of such distinctive features would nonetheless constitute strong evidence that excavates are descended from a common excavate ancestor.

In small flagellate protists, most 'conserved' morphological features are elements of the cytoskeleton and are usually parts of the flagellar apparatus (Sleigh, 1988; Moestrup, 2000). An 'alignment' of flagellar apparatuses is virtually a precondition for the identification of homologies that might be apomorphies for a particular group. This section is therefore split into two parts - (i) the first comprehensive comparison of the flagellar apparatuses of all excavate groups, and (ii) an account of the morphology and distribution of characters that appear to be distinctive for excavates and widespread amongst them, and are thus candidate apomorphies for Excavata.

\section{Organization of the flagellar apparatus}

Typical excavates. Initially, I will consider five groups: jakobids, Malawimonas, Trimastix, Carpediemonas and retortamonads. These 'typical excavates' have very similar and easily comparable flagellar apparatuses (Figs 2 and 3), yet they probably represent most or all of the phyletic diversity of excavates (see the section entitled 'Distinctive excavate features' below). Other taxa are considered individually afterwards. Jakobids and Malawimonas have two basal bodies, retortamonads and Trimastix have four and Carpediemonas has three (Simpson \& Patterson, 1999). The most posterior basal body is inferred to be the eldest, based on (limited) data on flagellar apparatus replication, and is named ' 1 ' (O'Kelly, 1993; Simpson et al., 2002b). Basal body 1 is associated with two microtubular roots, one roughly to the right of the basal body and one to the left. These run posteriorly to support the right and left walls of the feeding groove and have previously been termed the 'right' and 'left' roots. The most anterior basal

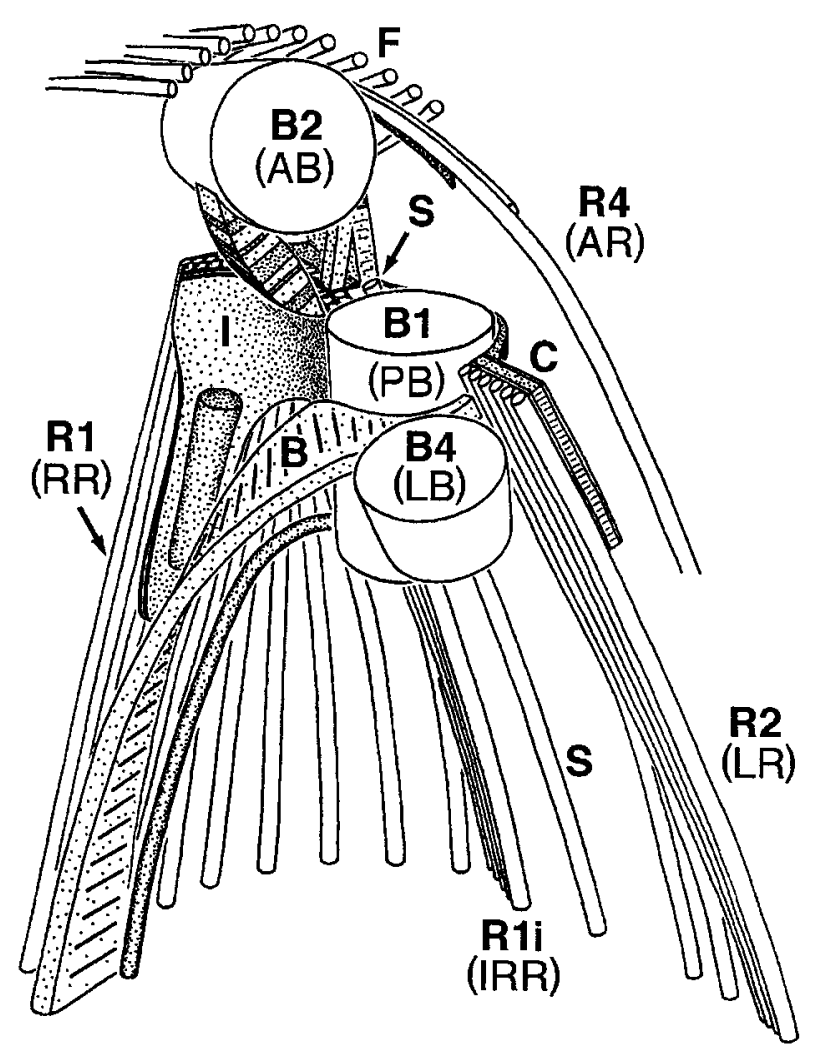

Fig. 2. Proximal flagellar apparatus of a 'typical' excavate, Carpediemonas membranifera, viewed from the ventral side. Diagram depicts basal bodies, flagellar microtubular roots and secondary microtubular structures, as well as major nonmicrotubular fibres. Names for various structures in the new terminology are in bold. Previous terminology is given in normal text in parentheses. Abbreviations (primary notation only): B1, basal body 1; B2, basal body 2; B4, basal body 4; B, B fibre; C, C fibre; F, dorsal fan of peripheral microtubules; I, I fibre; $\mathrm{R} 1$, root 1 (outer portion); R1i, inner portion of root 1 ; R2, root 2; R4, root 4; S, singlet root. Modified from Simpson \& Patterson (1999).

body is inferred to be the second eldest and is named ' 2 '. In Trimastix, Malawimonas and Carpediemonas, this is associated with one major microtubular root, previously termed the 'anterior root' (Brugerolle \& Patterson, 1997; O'Kelly, 1997; O'Kelly \& Nerad, 1999; Simpson \& Patterson, 1999; Simpson et al., 2000). This root originates on the most anterior side of the basal body and then curves leftward, usually running down the left side of the cell. It is associated with the nucleation of a 'dorsal fan' of microtubules that support the dorsal cell plasma membrane. The jakobid Jakoba incarcerata has a single microtubular root that is similar, but originates on the ventral side of the basal body and is not clearly associated with the dorsal fan (Simpson \& Patterson, 2001). No long microtubular root has been identified in other jakobids or in retortamonads (O'Kelly, 1997; O'Kelly \& Nerad, 1999). In the retortamonad Chilomastix cuspidata, there are two 


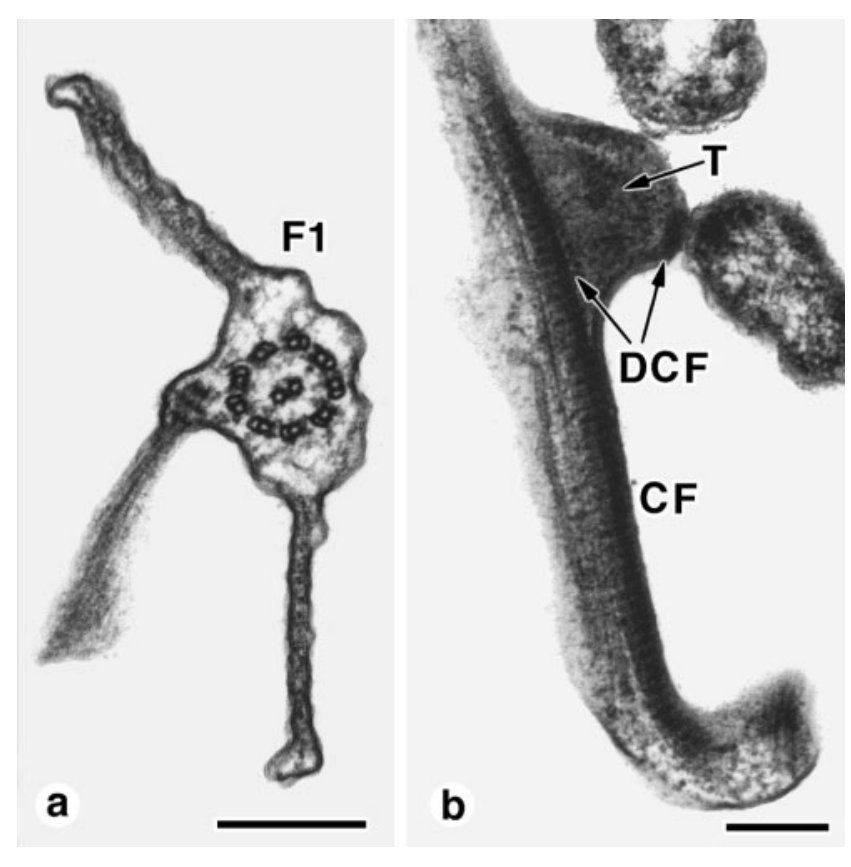

Fig. 3. Transmission electron micrographs of Carpediemonas membranifera. (a) Transverse section of flagellum 1 (base-to-tip view) showing flagellar vanes; (b) right margin of the groove at the extreme posterior of end of the cell, showing composite fibre in longitudinal section. The lateral expansion within the dense component of the composite fibre forming the 'tongue' structure is atypical. Abbreviations: F1, flagellum 1; CF, composite fibre; DCF, dense component of composite fibre; T, 'tongue' structure. Relabelled from Simpson \& Patterson (1999). Bars, $250 \mathrm{~nm}$.

short rootlets associated with the anterior-most basal body 'B' (Bernard et al., 1997; Simpson et al., 2000); these might be 'protoroots' that would mature as the roots associated with basal body 1 at the next round of cell division. Extra putative 'protoroots' are present in Trimastix marina (Simpson et al., 2000) and some Malawimonas cells (O’Kelly \& Nerad, 1999).

Universal terminology. When highlighting the similarity in flagellar rootlet patterns in diverse protists, Moestrup (2000) suggested a universal numbering system for flagellar microtubular roots. This has yet to be applied to excavates, with the exception of euglenozoans (Moestrup, 2000). Based on comparison with euglenozoans (see below), I infer that the right microtubular root of typical excavates corresponds to 'root 1' (R1) in euglenozoans, whilst the left microtubular root is 'root 2' (R2). The single root associated with basal body 2 in euglenozoans is identified as 'root 4' (R4) by Moestrup (2000). Based on similarity of function, this root would be homologous to the 'anterior' root of typical excavates (see below), which is therefore now named R4. This terminology is summarized in Figs 2 and 4.
Diplomonads. Most diplomonads have two opposed kinetids, each of which consists of four basal bodies. 'Enteromonads' normally have a single kinetid with four or two basal bodies. In each case, the most posterior flagellum, usually termed ' $R$ ', is associated most closely with the feeding grooves or cytopharyngeal tubes (where these are present) and with posteriorly directed microtubular roots (see below and Brugerolle, 1991a; Brugerolle \& Müller, 2000). The most anterior basal body, previously ' 1 ', is associated with a single root, the 'supranuclear fibre', that is directed more-or-less anteriorly and supports the plasma membrane, there being no separate array of peripheral microtubules (Brugerolle, 1991a). It is likely, then, that basal body ' $R$ ' is equivalent to basal body 1 in typical excavates and that the original basal body 1 is equivalent to basal body 2 of typical excavates. The supranuclear fibre is the most plausible homologue of R4.

In most diplomonads, a microtubular root, termed the 'cytostomal fibre', 'direct fibre' or 'funis', originates alongside basal body 1 of each kinetid (Kulda \& Nohynková, 1978; Brugerolle, 1991a; Brugerolle \& Müller, 2000). Possible exceptions in Enteromonas and Caviomonas require further examination (Brugerolle, 1975a; Brugerolle \& Regnault, 2001). Where determinable, this root is located on the equivalent of the right side of the basal body and runs posteriorly in association with the feeding groove or cytopharyngeal tube, when present. This suggests that the direct fibre is homologous to R1 (in Enteromonas, the so-called 'left fibre' may correspond to R1). In all diplomonads except Giardia, Octomitus, Brugerolleia and Caviomonas, a second microtubular root, the 'indirect fibre' or 'infranuclear fibre', is associated less closely with basal body 1 (Brugerolle, 1991a; Desser et al., 1993; Brugerolle \& Regnault, 2001) and originates on the equivalent of the left side of basal body 1, at least in Trepomonas (Fig. 4f). This 'infranuclear fibre' is the most likely equivalent of R2, but further data on its site of origin in diverse diplomonads would be valuable.

Heterolobosea. The groove-bearing heteroloboseids Psalteriomonas, Lyromonas and Percolomonas have four parallel basal bodies that are arranged as a tetrad. In Tetramitus, the four basal bodies are arranged as a mirror-image 'L'. In Psalteriomonas, the most posterior basal body (originally termed '4') is associated with one large microtubular root, the curved 'MTOR', which supports the right wall of the groove (Broers et al., 1990). The second-most anterior basal body, originally ' 2 ', nucleates a root with two microtubules on its outer side (Fig. 10 in Broers et al., 1990). This associates with an electron-dense 'gully structure', which in turn is closely associated with the peripheral microtubules (see Fig. 4g). It is inferred that the posterior-most basal body, ' 4 ', is actually basal body 1 , the MTOR is R1, basal body 2 is correctly labelled and the microtubules associated with it might be R4. Lyromonas is similar, except that the presence of the putative R4 is not confirmed. Tetramitus 


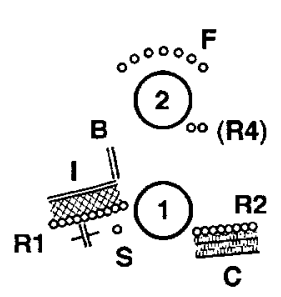

Jakobid
a (Jakoba incarcerata)

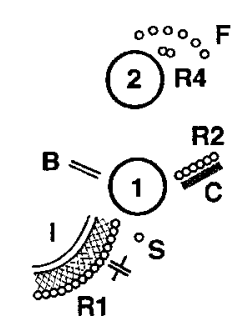

b $\begin{gathered}\text { Malawimonas } \\ \text { jakobiformis }\end{gathered}$

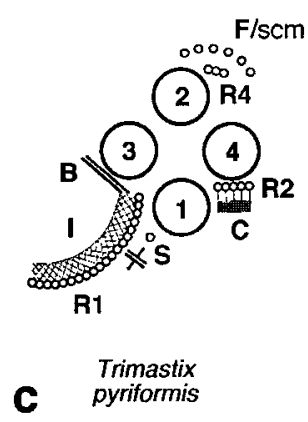

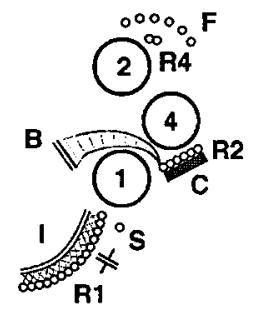

Carpediemonas membranifera

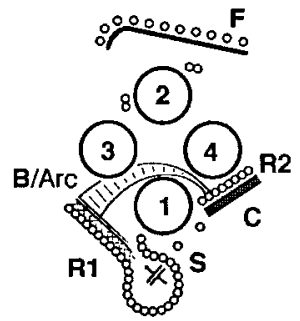

Retortamonad

e (Chilomastix cuspidata)
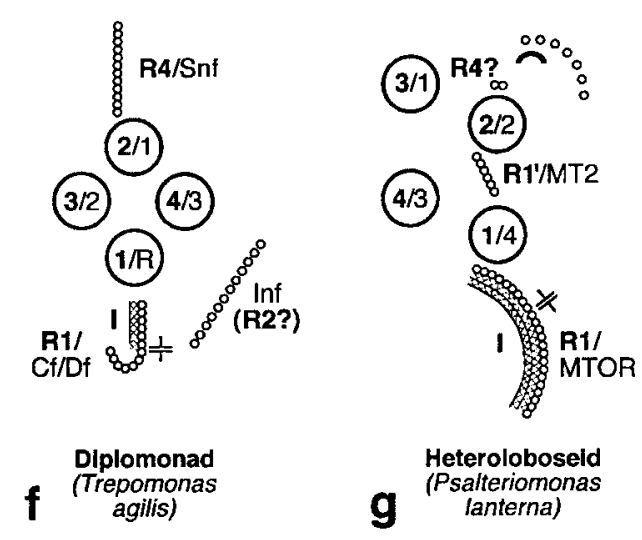

Diplomonad
(Trepomonas
agilis)

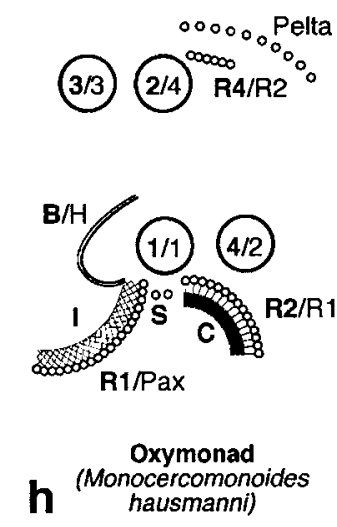

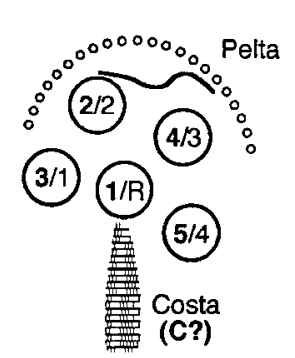
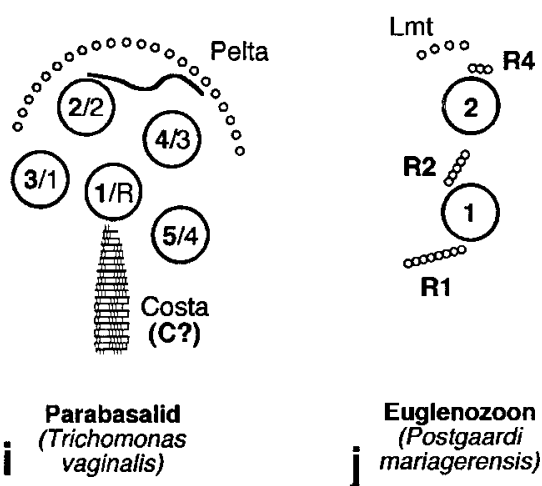

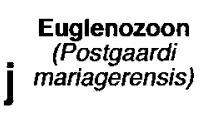

Fig. 4. Diagrammatic representations of the proximal cytoskeletons of Excavata. Diagrams are presented according to the technique of Sleigh (1988). Thus, all basal bodies are viewed in the 'tip-down' orientation and microtubular roots are aligned similarly to their associated basal bodies. Large circles represent basal bodies; small circles represent microtubules. Some important non-microtubular fibres are also depicted, as are some of the microtubules that support the cell periphery. Terminology used in this paper is given in bold; previous terminology is given in normal type afterwards. Double-arrow symbols in parts a-g indicate the approximate position of splitting of R1 as this root travels away from the basal bodies (R1 does not split in parts h-j). (a) Data from Simpson \& Patterson (2001); the position of the B fibre and presence of R4 are atypical for jakobids generally. (b) Data from O'Kelly \& Nerad (1999). (c) Data from O'Kelly et al. (1999). (d) Data from Simpson \& Patterson (1999); note that the B fibre has been drawn in two orientations. (e) Data from Bernard et al. (1997). (f) Data from Brugerolle et al. (1973a) and Eyden \& Vickerman (1975), with previous terminology from Brugerolle (1991a) and Brugerolle \& Müller (2000). The positions of R1 and Inf (R2?) are approximate. A possible singlet root (S) is present in Giardiinae. (g) Data from Broers et al. (1990). (h) Data from Radek (1994) and Simpson et al. (2002b). (i) Data from Nielsen et al. (1966), with previous terminology as per Brugerolle (1991). (j) Data from Simpson et al. (1997), applying the terminology of Moestrup (2000). Abbreviations (primary notation only): 1, basal body 1 ; 2 , basal body 2 ; 3, basal body 3; 4, basal body 4; B, B fibre; C, C fibre; F, dorsal fan of peripheral microtubules; I, I fibre; R1, root 1; R1', prominent 'protoroot' that will mature to R1 in the next round of cell division; R2, root 2; R4, root 4; S, singlet root. Parts a-e and h are modified from Simpson et al. (2002).

rostratus is broadly similar, except that basal body 1 was originally labelled ' 3 ', with R1 being the 'posterior-most' of two curved 'microtubular sheaves' (Balamuth et al., 1983; see below). Percolomonas cosmopolitus is also similar, with basal body 1 originally called basal body 4 and basal body 2 being correctly labelled (contra O'Kelly, 1993). Microtubular root 'B' (Fenchel \& Patterson, 1986) is R1. The original reconstruction of Percolomonas includes a separate ' $\mathrm{C}$ ' root on the left of what is now basal body 1 (Fenchel \& Patterson, 1986). However, reexamination of two Percolomonas isolates (unpublished data; G. Brugerolle, personal communication) demonstrates that this structure is actually derived from R1 (see below). Percolomonas cosmopolitus has another root, originally termed ' $\mathrm{A}$ ', that originates from the anterior end of the flagellar apparatus and descends down the right side of the cell. This might be R4, although its site of origin is unclear and its rightward direction would be atypical.

In Tetramitus rostratus, basal body 2 is also associated with a curved 'microtubular sheath' that is very similar to the R1 associated with basal body 1 (Balamuth et al., 1983). The most straightforward interpretation is that this structure will 'mature' to a true R1 associated with basal body 1 in the next cell division. Psalteriomonas and Lyromonas each possess a smaller and unadorned microtubular root, 
previously termed MT2 and MT3, respectively, that lies between basal bodies 1 and 2 (Broers et al., 1990, 1993). This has sometimes been considered to be associated with basal body 1 and to be equivalent to the R2 of typical excavates (Simpson \& Patterson, 1999). However, more detailed study shows that this root is actually associated with basal body 2 and also represents an unmatured R1 root (G. Brugerolle, personal communication). This structure is not documented in Percolomonas cosmopolitus. Current evidence therefore suggests that heteroloboseids lack R2.

Oxymonads. Oxymonads vary markedly in size and appearance (Brugerolle \& Lee, 2000a; Brugerolle \& Müller, 2000), ranging from elongate cells hundreds of micrometres long that attach to the gut wall of their host (e.g. Pyrsonympha) to small, free-swimming cells (e.g. Monocercomonoides). Oxymonads lack a feeding groove, but do possess a complex cytoskeleton (Brugerolle \& Müller, 2000). Recently, Simpson et al. (2002b) re-examined the flagellar apparatus of Monocercomonoides hausmanni and confirmed a cytoskeletal organization similar to that of typical excavates. In M. hausmanni, the most posterior basal body, 1, is associated with two microtubular roots. The 'rightmost' is the microtubular component of the so-called 'preaxostyle' and the 'leftmost' was previously called R1 (the latter is absent in most other oxymonads). Simpson et al. (2002b) equated the preaxostyle with what is now R1 of typical excavates and equated the old R1 with what is now R2. One of the most anterior basal bodies (previously 4) is associated with the origin of another root, previously R2, that underlies the microtubules that support the plasma membrane (i.e. the 'pelta'). These structures are now equated with basal body 2 and R4 (Simpson et al., 2002b).

Parabasalids. The cytoskeletons of parabasalids are unusual amongst flagellates as they are usually complex, yet include no distinct flagellar microtubular roots. The primary structures associated with the basal bodies are a series of non-microtubular fibres (Brugerolle \& Lee, 2000b). The main microtubular cytoskeletal structure, the pelta-axostyle complex (Brugerolle, 1991a; Brugerolle \& Lee, 2000b), is probably the equivalent of the peripheral microtubules of many other cells, even though it is internalized. The basic parabasalid flagellar apparatus has four 'privileged' basal bodies, three anteriorly directed units (usually labelled 1-3) and a fourth posteriorly directed basal body labelled 'R' (Brugerolle, 1991a; Brugerolle \& Lee, 2000b). Details of basal body replication and inheritance are unclear (Brugerolle, 1991a). Based on directional similarity, $\mathrm{R}$ is equated with basal body 1 of typical excavate taxa. The central anterior basal body, 2, is tentatively equated with basal body 2 of typical excavates, based on its central position and closest association to the pelta microtubules.

Euglenozoa. Most euglenozoans have two basal bodies that lie parallel or acutely to each other. The basal body that gives rise to the posteriorly directed flagellum is the eldest, 1 (Farmer \& Triemer, 1988; Moestrup, 2000). Generally, two microtubular roots associate with basal body 1, the 'ventral' root and the 'intermediate' root (Simpson, 1997). Moestrup (2000) equates the ventral root with R1 and the intermediate root with R2. R1 is located on the 'outer' side of basal body 1, similar to the R1 of heteroloboseids in particular (e.g. Broers et al., 1990, 1993). The euglenozoan R2 lies on the opposite side of the basal body to R1. Although euglenozoans lack a feeding groove, in most taxa, R1 is continuous with microtubules that support the feeding apparatus (the possible exception being some euglenids; Leander et al., 2001), recalling the role of $\mathrm{R} 1$ in excavate taxa that have discrete mouths at the base of the groove (e.g. retortamonads, Trimastix marina). Given these similarities, R1 and R2 of euglenozoans are equated with their namesakes in other excavates. In euglenozoans, there is a single root associated with basal body 2. Based on its transformation into R2 during flagellar apparatus maturation (Brugerolle, 1992), Moestrup (2000) identified this root as R4. The root is associated with the origins of the peripheral microtubules, similarly to the formerly called 'anterior' root (now R4) of many typical excavate taxa.

\section{Distinctive excavate features}

Although the flagellar apparatuses of excavate taxa are at least broadly similar, no single component of the arrangement of basal bodies and microtubular roots is unique to excavates. 'Three to four microtubular roots derived from the two eldest basal bodies' is a common organization among protists (Moestrup, 2000; Cavalier-Smith, 2002). However, several other cytoskeletal elements, mostly associated with particular microtubular roots or flagella, are present in many excavates, but have no clear homologues outside the excavates. These are potential apomorphies for the Excavata clade. A summary of the presence and absence of distinctive features is given in Table 1.

Table 1. Distribution of distinctive excavate features in the ten established groups of Excavata

Taxa: 1, Jakobids; 2, Malawimonas; 3, Trimastix; 4, Carpediemonas; 5, retortamonads; 6, diplomonads; 7, Heterolobosea; 8, oxymonads; 9, parabasalids; 10, Euglenozoa. + , Presence of feature; ?, arguable homology; ND, no appropriate data.

\begin{tabular}{|lllllllllll|}
\hline Feature & $\mathbf{1}$ & $\mathbf{2}$ & $\mathbf{3}$ & $\mathbf{4}$ & $\mathbf{5}$ & $\mathbf{6}$ & $\mathbf{7}$ & $\mathbf{8}$ & $\mathbf{9}$ & $\mathbf{1 0}$ \\
\hline Feeding groove & + & + & + & + & + & + & + & & & \\
I fibre & + & + & + & + & + & + & + & + & & \\
B fibre & + & + & + & + & + & & & + & & \\
C fibre & + & + & + & + & + & & & + & $?$ & \\
Split R1 & + & + & + & + & + & + & + & & & \\
Singlet root & + & + & + & + & + & $?$ & & + & & \\
Flagellar vanes & + & + & + & + & + & & & & & \\
Composite fibre & + & ND & + & + & + & & & & & \\
& & & & & & & & & & \\
\hline
\end{tabular}


I fibre. The I fibre is a band of material that adheres to the ventral/inner face of $\mathrm{R} 1$ at its most anterior end (Fig. 2). The I fibre was first distinguished in the jakobid Reclinomonas (O'Kelly, 1997) and has since been identified in Jakoba libera, Jakoba incarcerata and Histiona (O'Kelly, 1997; O'Kelly \& Nerad, 1999; Simpson \& Patterson, 2001), as well as Malawimonas (O'Kelly \& Nerad, 1999), Carpediemonas (Simpson \& Patterson, 1999), Trimastix (O'Kelly et al., 1999; Simpson et al., 2000), retortamonads (Fig. 9 in Brugerolle, 1977; Fig. 4a-f in Bernard et al., 1997; O'Kelly \& Nerad, 1999) and heteroloboseid flagellates (Fig. 10 in Balamuth et al., 1983; Fig. 6d in Fenchel \& Patterson, 1986; Fig. 13 in Broers et al., 1990; Fig. 6 in Broers et al., 1993; O’Kelly \& Nerad, 1999; Simpson \& Patterson, 1999).

To date, I fibres have not been identified in diplomonads. However, in Enteromonas and Trepomonas, structures similar to the I fibres of retortamonads adhere to the inner face of R1 (Fig. 12 in Brugerolle et al., 1973a; Fig. 18 in Brugerolle, 1975a; Fig. 12 in Brugerolle, 1991b). Similar material is also present at the anterior end of R1 in Spironucleus (Fig. 3 in Brugerolle et al., 1973b; Fig. 8 in Brugerolle et al., 1980) and Giardia (Fig. 8 in Brugerolle, 1975b). Material with an uncertain substructure adheres along the inner/ventral face of the R1 of Octomitus (Brugerolle et al., 1974) and Brugerolleia (Fig. 4 in Desser et al., 1993). More precise data would be desirable, but it is plausible that these various structures are also I fibres.

The preaxostyle complex of Monocercomonoides and other oxymonads includes a latticework paracrystalline component that is nearly indistinguishable from the I fibre of Trimastix (Brugerolle, 1991a; Simpson et al., 2002b). As with I fibres, this material attaches to the equivalent of the ventral face of R1 and is considered to be homologous.

B fibre. The B fibre is a ribbon-like structure that follows the anterior portion of R1, lying immediately to the ventral side of the root (Fig. 2). First described in Jakoba libera by Patterson (1990), similar B fibres have since been identified in other jakobids (O'Kelly, 1997; O'Kelly \& Nerad, 1999; Simpson \& Patterson, 2001), Malawimonas (O’Kelly \& Nerad, 1999), Carpediemonas (Simpson \& Patterson, 1999) and Trimastix (O'Kelly et al., 1999; Simpson et al., 2000). On close inspection, these B fibres all have a bilaminar appearance. In all cases except Carpediemonas, the B fibre originates against the extreme anterior end of R1 or against the adjacent wall of basal body 1. In Carpediemonas, the B fibre originates against $\mathrm{R} 2$, then arches across the ventral face of the basal body to associate with R1 (Fig. 2; Simpson \& Patterson, 1999). The B fibres of at least Jakoba incarcerata, Carpediemonas membranifera and Trimastix marina display similar $30 \mathrm{~nm}$ 'horizontal' striations. In the oxymonad Monocercomonoides, a fibrous sheet with a bilaminar appearance and $30 \mathrm{~nm}$ lateral striations originates adjacent to R1 and basal body 1 (Simpson et al., 2002b). Originally called the hook-like fibre (Radek, 1994), this actually appears to be a B fibre (Simpson et al., 2002b).

Simpson \& Patterson (1999) argued that the distinctive 'arched' fibre of retortamonads (Bernard et al., 1997; Brugerolle, 1973, 1977) is actually homologous to B fibres. Although arched fibres lack the bilaminar appearance of B fibres, they show similar $30 \mathrm{~nm}$ lateral striations (Bernard et al., 1997) and their positions relative to $\mathrm{R} 1$ and $\mathrm{R} 2$ are similar to the B fibre of Carpediemonas. From hereon, unless specified otherwise, the term 'B fibre' is used to cover both 'B fibres' sensu stricto and the arched fibres of retortamonads.

C fibre. Patterson (1990) first identified the C fibre in the jakobid Jakoba libera, where it is an elongate multilayered structure that adheres to the dorsal side of R2. Similar C fibres have since been identified in other jakobids (Fig. 8 in Mylnikov, 1989; O’Kelly, 1997; O'Kelly \& Nerad, 1999; Simpson \& Patterson, 2001). Generally less elaborate, but otherwise similar structures have been identified in Trimastix (O'Kelly et al., 1999; Simpson et al., 2000), retortamonads (Figs 9-12 in Brugerolle, 1973; Fig. 9 in Brugerolle, 1977; Fig. 4c-f in Bernard et al., 1997; O'Kelly \& Nerad, 1999), Carpediemonas (Fig. 2; Simpson \& Patterson, 1999) and Malawimonas (O'Kelly \& Nerad, 1999). No equivalent of the $C$ fibre has been found in heteroloboseids, diplomonads or euglenozoans. However, in the oxymonad Monocercomonoides, a C fibre similar to that of Trimastix is associated with the anterior 'dorsal' portion of R2 (Simpson et al., 2002b). Simpson \& Patterson (2001) argued that the 'costal fibre' present in some parabasalids might be homologous to the $\mathrm{C}$ fibre, based on substructural similarities between the $\mathrm{C}$ fibre of jakobids and the 'B-type' costa of many trichomonads, for example Trichomonas (Brugerolle \& Lee, 2000b). Like the C fibre, this costa is associated most closely with basal body 1 (Nielsen et al., 1966; Brugerolle, 1991a).

Split R1. In most excavate flagellates, R1 splits shortly after its origin into distinct inner and outer portions (Fig. 2). This is documented clearly in most jakobids studied (Fig. 7 in Mylnikov, 1989; O’Kelly, 1997; Simpson \& Patterson, 2001), Malawimonas (O'Kelly \& Nerad, 1999), Carpediemonas (Simpson \& Patterson, 1999) and retortamonads (Brugerolle, 1973, 1977; Bernard et al., 1997), where the inner portion of R1 was called the 'hook band' (Bernard et al., 1997). A discrete inner portion of R1 is also present in Trimastix (O'Kelly et al., 1999; Simpson et al., 2000); however, at least in Trimastix marina, it is actually 're-assembled' from microtubules that diverge one at a time from the inner section of R1.

In addition to R1, most diplomonads have multiple small bands of microtubules that run down the cell (see above). For Brugerolleia, it is known that one such band is derived from the inner portion of R1 (Desser et al., 1993). A similar organization can be inferred for Octomitus (Figs 9 and 10 in Brugerolle et al., 1974) and Giardia (Figs 8 and 9 in 
Brugerolle, 1975b). In Trepomonas, there are two major microtubular bands in the most anterior portion of the groove, in addition to the infranuclear fibre (Fig. 12 in Brugerolle et al., 1973a). These four diplomonads are regarded as having discrete inner and outer portions of R1. However, in Spironucleus barkhanus, which has three microtubular bands, only one of the bands is continuous with R1; the other two derive from the indirect fibre of the opposite kinetid (compare Fig. 6a and $\mathrm{c}$ in Sterud et al., 1997), indicating that a split R1 is not universal in diplomonads.

In the heteroloboseids Psalteriomonas and Lyromonas, R1 splits into inner and outer portions, previously referred to as left and right fibres, respectively (Broers et al., 1990, 1993). For Percolomonas cosmopolitus, examination of unpublished micrographs (T. Fenchel and D. J. Patterson, unpublished results) demonstrates that R1 splits soon after its origin. The ' $\mathrm{C}$ root' reported by Fenchel \& Patterson (1986) is actually the inner portion of R1.

Singlet root. The 'singlet root' was originally distinguished by O'Kelly (1997) in the jakobid Reclinomonas. It is a single microtubule that originates from the dorsalmost angle between the right root and the basal body, then runs along the floor of the groove (Fig. 2). Similar singlet roots have since been identified in Jakoba incarcerata, Malawimonas, Trimastix, Carpediemonas and the retortamonad Chilomastix cuspidata (O'Kelly \& Nerad, 1999; O'Kelly et al., 1999; Simpson \& Patterson, 1999, 2001; Simpson et al., 2000). A singlet root also seems to be present in the jakobid Histiona (Fig. 11 in Mylnikov, 1989; O'Kelly \& Nerad, 1999). Simpson et al. (2002b) identified a probable singlet root in the oxymonad Monocercomonoides.

Singlet roots have not been identified previously in heteroloboseids or diplomonads. However, in all diplomonads, there are small groups of microtubules that continue posteriorly in association with the major microtubular roots (Siddall et al., 1992; Desser et al., 1993). In Octomitus, at least one of a pair of microtubules originates in the angle between the 'dorsal' side of the right root and the posterior basal body (Fig. 9 in Brugerolle et al., 1974) and similar arrangements can be inferred for Giardia (Figs 6 and 7 in Friend, 1966) and Brugerolleia (Figs 4 and 11 in Desser et al., 1993). It is possible that this structure is homologous to the singlet roots of other excavate taxa. However, Spironucleus barkhanus, at least, seems to lack singlet microtubular roots, as all relevant microtubules appear to be continuous with either the right root or the indirect fibre (compare Figs 6a and c in Sterud et al., 1997).

Flagellar vanes. In retortamonads, jakobids, Malawimonas, Trimastix and Carpediemonas, flagellum 1 has prominent vanes for much of its length (Fig. 3a; Simpson \& Patterson, 1999). O'Kelly (1993) argued that the vanes of retortamonads, jakobids and Malawimonas are homologous, a proposal later extended to Trimastix and Carpediemonas (O'Kelly et al., 1999; Simpson \& Patterson, 1999). One, two or three vanes are present in each taxon. The single vanes of jakobids lie on the dorsal side of the flagellum (Mylnikov, 1989; Patterson, 1990; Flavin \& Nerad, 1993; O’Kelly, 1997; Simpson \& Patterson, 2001). The single vane of Malawimonas is located ventrally (O'Kelly \& Nerad, 1999). Double vanes, found in Trimastix and some retortamonads (Chilomastix spp.), lie opposed on the dorsal and ventral sides (Brugerolle, 1973; Bernard et al., 1997; Brugerolle \& Patterson, 1997; O’Kelly et al., 1999; Simpson et al., 2000). Three vanes (dorsal, ventral and lateral) are only known in Carpediemonas (Fig. 3a) and the retortamonad Retortamonas agilis (Brugerolle, 1977; Simpson \& Patterson, 1999). Where studied in detail (Reclinomonas americana, Jakoba incarcerata, Malawimonas, Carpediemonas and Chilomastix cuspidata), ventral vanes originate with a discrete, rounded supporting element, whereas dorsal vanes originate more diffusely (Bernard et al., 1997; O’Kelly, 1997; O’Kelly \& Nerad, 1999; Simpson \& Patterson, 1999, 2001). Where studied (two jakobids, two retortamonads, two Trimastix and Carpediemonas), the vane lamellae are striated perpendicularly to the axoneme (Brugerolle, 1977; Mylnikov, 1989; Bernard et al., 1997; Brugerolle \& Patterson, 1997; Simpson \& Patterson, 1999, 2001; Simpson et al., 2000). The similarity in vane substructure and mode of origin across a diversity of taxa supports their homology.

In heteroloboseids and diplomonads, flagellar vanes are known only in Psalteriomonas lanterna (Broers et al., 1990) and Giardia (Friend, 1966; Holberton, 1973; Brugerolle, 1975b). The locations of these vanes are different from other excavates. In Psalteriomonas, all flagella have similar vanes. In Giardia, the vanes are located on one lateral flagellum from each kinetid, not the posterior flagellum (Brugerolle, 1975b). No data are available on their substructure or mode of origin. On present data, the vanes of Giardia and Psalteriomonas are not considered to be homologous to those in other excavates (O'Kelly, 1997).

Composite fibre. The composite fibre was identified as a widespread structure by Simpson \& Patterson (1999), following Brugerolle's observations of 'cytostomal fibres' in retortamonads (Brugerolle, 1973, 1977). The composite fibre of Carpediemonas originates in association with the dorsal/outer side of R1 about halfway down the groove, immediately before the termination of most of the root microtubules (Simpson \& Patterson, 1999). The fibre is striated longitudinally and cross-striated, but has a nonstriated, electron-dense component on the innermost side (Fig. 3b). Cross-striations are spaced at $\sim 30 \mathrm{~nm}$. Similar composite fibres are present in jakobids (Fig. 7 in Mylnikov, 1989; Fig. 4c in Patterson, 1990; Fig. 13 in Flavin \& Nerad, 1993; Simpson \& Patterson, 1999, 2001), with $30 \mathrm{~nm}$ cross-striations documented in Jakoba incarcerata. The fibre is also present in Trimastix (Fig. 19 in Brugerolle \& Patterson, 1997; Simpson et al., 2000), although it was originally misidentified as a portion of the 
C fibre (Brugerolle \& Patterson, 1997; Simpson \& Patterson, 1999). The structures in retortamonads are similar, except that the dense component is cryptic (Brugerolle, 1973, 1977; Bernard et al., 1997). The relevant data are lacking for Malawimonas. No diplomonads or heteroloboseids that have been studied in detail have a composite fibre.

\section{Summary of morphological data}

In addition to having very similar cytoskeletons overall, the five 'typical excavates' share approximately seven discrete morphological characters that have not been recorded in other major groups of eukaryotes. Whilst it is certainly possible that one or more of these homology arguments may be incorrect (i.e. the character has evolved convergently), it seems unlikely that most, or all, are so flawed. Even without reference to a phylogeny, there is a strong case that all typical excavates are descended from a cell that was essentially a 'typical excavate' in terms of morphology.

Diplomonads, heteroloboseids and oxymonads each share some (three to four), but not all, of these distinctive features. In the absence of a phylogenetic tree, morphological data suggest, albeit much more weakly, that these taxa are also descended from a common excavate ancestor (fewer convergences need to be assumed). The case for a common origin with other excavates would be bolstered greatly by robust phylogenetic evidence that shows specific relationships with one or more of the typical excavates (see below).

There is almost no evidence from morphology alone that either parabasalids or euglenozoans descended from excavate ancestors. The case that these taxa are excavates rests almost entirely on other evidence, especially molecular phylogenies (see below).

\section{Relationships amongst excavates Morphological data}

Despite the importance of structural data to the case for Excavata as a clade, contemporary workers with a structural perspective have not employed formal analyses when considering relationships amongst excavates (e.g. O'Kelly \& Nerad, 1999; Simpson \& Patterson, 2001; Cavalier-Smith, 2002). This is partly because the question of whether excavate taxa are related to each other at all has been paramount. Most of the morphological characters by which excavates can be compared are not scorable in other eukaryotes, making it difficult to conceive a credible test of the excavate hypothesis by using a formal analysis of these data.

Here, the first formal analysis of morphological data for excavates is attempted. No non-excavates are considered, so the analysis seeks only to determine the relationships amongst excavates, not to examine whether excavates are related to the exclusion of all other eukaryotes. In this important respect it differs from the molecular analyses reviewed later.

Methods. For the analyses, currently recognized genera are used as terminals in most cases, but with several exceptions. Firstly, the monophyly of the genera Trimastix and Jakoba is debated (Simpson et al., 2000; Edgcomb et al., 2001; Simpson \& Patterson, 2001) and the two well-documented nominal species from each are included separately. Secondly, only a few representative heteroloboseids with highly organized flagellate phases are considered, whereas the highly 'reduced' diplomonad Caviomonas (Brugerolle \& Regnault, 2001) is not considered. Thirdly, the three groove-lacking groups (oxymonads, parabasalids and Euglenozoa) are difficult to score for many characters and, for simplicity, are each included as a single terminal, with contemporary knowledge of their internal phylogeny used to assign states when ancestral conditions are known with confidence (for example, in scoring parabasalids as parasitic/endocommensal, but Euglenozoa as free-living). A documented character matrix and detailed character-by-character commentaries are available on request.

Initially, all taxa and 73 informative characters were included. Subsequently, oxymonads, parabasalids and Euglenozoa were excluded, leaving 71 informative characters. Analyses were run in PAUP ${ }^{\star}$ b10 (Swofford, 2000) under unweighted parsimony with 'or' coding for multiple states, 'unscorable' characters coded as uncertainty and using 100 random additions and tree bisection-reconnection (TBR) for tree searching. Tree robustness was assessed by Bremer support (decay indices) by using AUTODECAY 4.0.2 (Eriksson, 1999) with the same search strategy.

Backbone topology. When all taxa are included, four shortest trees of 179 steps are found. All groups with multiple terminals are recovered as clades. Most of the backbone topology is the same in all shortest trees, but resolved elements receive minimal support (Fig. 5a). Many of the relationships recovered between major groups are contradicted by strongly supported molecular phylogenies (see below). With the reduced taxon set, 35 shortest trees of 154 steps are found. The $75 \%$ threshold consensus of these 35 trees is shown in Fig. 5b. With the exception of one minimally supported clade (retortamonads/ diplomonads), the backbone collapses. Whilst some individual characters support some of the strong groupings that are indicated by molecular phylogenetic approaches (see Classification, below), available morphological data analysed within a parsimony framework do not illuminate high-level relationships amongst excavates. Further discussion considers relationships at the subgroup level.

Monophyly of individual taxa. As no outgroup was included, all inferred relationships carry the caveat that they may be interrupted by the root of the tree. Provided that the root does not lie within any of the recognized 


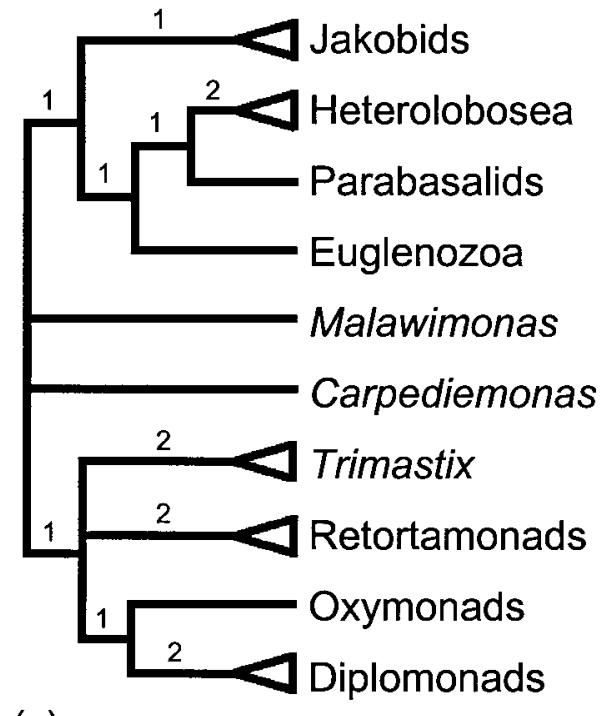

(a)

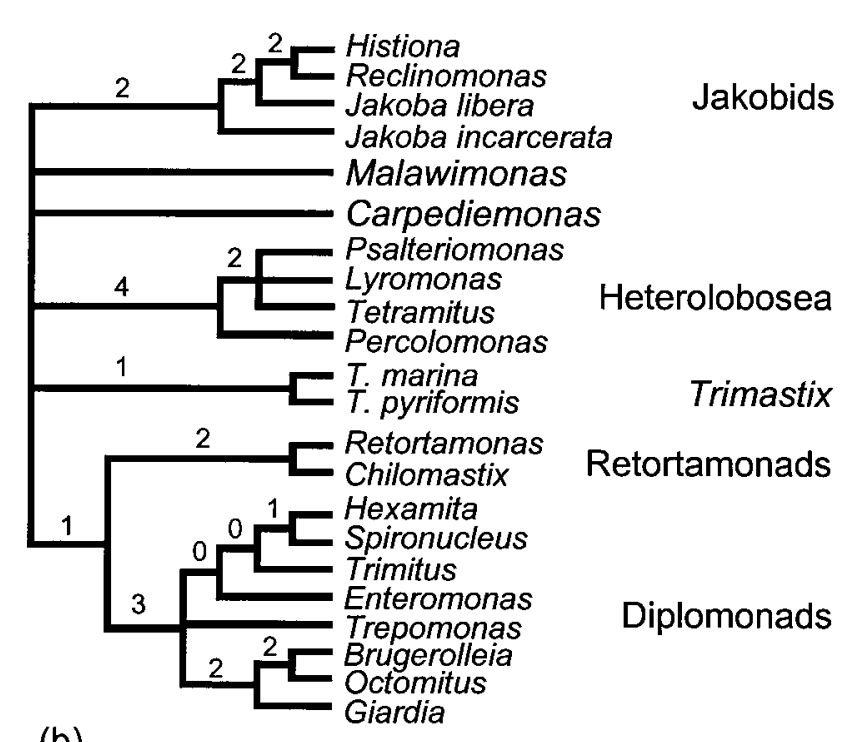

(b)

Fig. 5. Phylogenetic trees of Excavata from parsimony analysis of morphological data. (a) Strict consensus of the four most parsimonious trees when all taxa are included (groups with multiple terminals represented as radiations); (b) $75 \%$ threshold consensus tree (of 35 best trees) when oxymonads, parabasalids and Euglenozoa are excluded. Bremer support values for individual branches are shown ( 0 indicates a branch that is not present in all best trees).

taxa, these unrooted analyses confirm the monophyly of each subgroup where multiple taxa have been examined. Trimastix marina and Trimastix pyriformis form a clade to the exclusion of other excavate taxa, with weak support. Jakobids form a moderately supported clade that includes Jakoba incarcerata, which does not generally branch with other jakobids in SSU-rRNA and tubulin phylogenies (see below and Edgcomb et al., 2001; Simpson et al., 2002c). Heteroloboseids form a well-supported clade, with Percolomonas basal within this clade. Retortamonads are also monophyletic. Diplomonads, including 'enteromonads', form a moderately strong clade. This contradicts most SSU-rRNA analyses, which place retortamonads weakly within diplomonads as sisters to Giardia (Silberman et al., 2002; Simpson et al., 2002c).

Relationships amongst jakobids. Within jakobids, the lorica-bearing taxa Reclinomonas and Histiona always form a clade, to the exclusion of Jakoba libera and Jakoba incarcerata. Jakoba is not monophyletic, with Jakoba incarcerata being basal amongst jakobids (with moderate support). Jakoba incarcerata may not belong in Jakoba, although this possibility requires further testing once data become available from other jakobids.

Relationships amongst diplomonads. This analysis does not completely resolve the relationships amongst diplomonads. The only moderately supported grouping is Giardiinae [Giardia (Octomitus, Brugerolleia)]. Giardiinae is also monophyletic in an earlier morphological cladistic analysis of diplomonads (Siddall et al., 1992). These authors' analysis agrees with earlier intuitive accounts in the placement of Giardiinae within hexamitids (Brugerolle, 1975c). This is contradicted by strong molecular evidence for the monophyly of Hexamitinae (represented by Hexamita, Spironucleus and Trepomonas), both from phylogenetic trees and from the use of an alternative genetic code by hexamitids, but not by Giardia (Keeling \& Doolittle, 1997; Silberman et al., 2002). In contrast to the results of Siddall et al. (1992), the current morphological analysis is equivocal, with Giardiinae placed within Hexamitinae in some best trees, but as the basal diplomonad branch in others. This at least indicates the lack of a consistent 'morphological signal' that conflicts with the strong molecular signal for hexamitid monophyly.

The positions of the 'enteromonads' (Enteromonas and Trimitus) are also noteworthy. Enteromonads differ from other diplomonads in that they (usually) have a single nucleus and kinetid (Brugerolle, 1975a; Kulda \& Nohynková, 1978). There are no published molecular data. Previous intuitive and cladistic morphological accounts place enteromonads as a basal grade (or clade) relative to 'true' diplomonads (Brugerolle, 1975a; Siddall et al., 1992; Brugerolle \& Müller, 2000). By contrast, in this study, neither Enteromonas nor Trimitus falls basal to other diplomonads. In $20 \%$ of the best trees from the restricted analysis, enteromonads form a clade as sister to (Hexamita, Spironucleus), but otherwise they form separate branches within diplomonads. Enteromonads may have descended from true diplomonad ancestors, rather than representing an ancestral diplomonad condition. Enteromonads may also be polyphyletic. 


\section{Molecular approaches}

The sole molecular dataset available at present that includes representatives from all ten 'established' groups of excavates is that for SSU-rRNA (Simpson et al., 2002c). This dataset also includes the collodictyonid Diphylleia (Brugerolle et al., 2002), which turns out not to be strongly related to any excavate group (Fig. 6). Here, I discuss the evolutionary positions of excavates as inferred by using this marker and compare them briefly with results obtained by using other nuclear-encoded (protein) markers.

Methods. For this summary analysis, SSU-rRNA gene sequences from excavates were aligned by eye with sequences from other eukaryotes, with 56 taxa and 997 unambiguously aligned positions retained (alignment available on request). Taxa that contribute short terminal branches were used where possible. Some non-critical and highly divergent groups were excluded (for example, microsporidia and foraminifera), as were sequences with unusual G $+\mathrm{C}$ contents (most notably, Giardia). Phylogenetic analysis was performed with PAUP ${ }^{\star}$ b10 by using minimum evolution from maximum-likelihood distance estimates under a Tamura-Nei substitution model, empirical base frequencies and a 'four-category discrete approximation to a $\Gamma$ distribution plus invariable sites' model for among-site rate variation (with all parameters estimated initially from a maximum-parsimony tree). The tree search used 100 random-addition replicates with TBR rearrangements, with bootstrap support values calculated

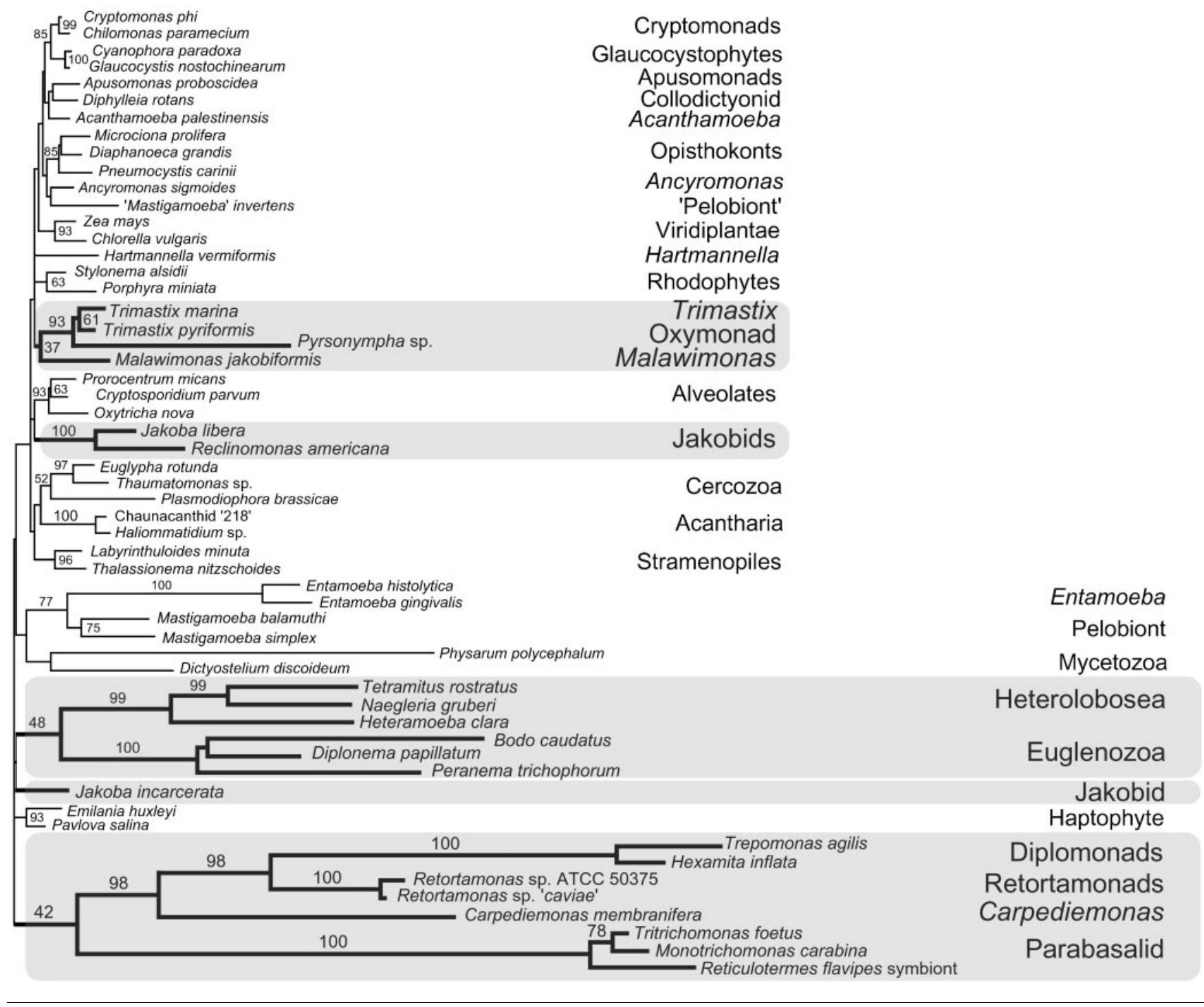

Fig. 6. Small-subunit rRNA tree of eukaryotes, including all excavate groups. The tree was generated from maximumlikelihood distance estimates with a TrN DNA substitution model and a ' $\Gamma+$ invariable sites' model for among-site rate heterogeneity. Excavate groups are shown in bold type and shaded. Bootstrap support values over $50 \%$ are shown; some important smaller values are also included. 
from 500 bootstrap replicates (three random additions with TBR per replicate). The best tree is shown in Fig. 6 .

Apparent non-monophyly of Excavata. As with virtually all previous analyses, excavates do not form a single clade, instead falling in several places in the tree (Edgcomb et al., 2001; Simpson et al., 2002c). However, the backbone of the tree is poorly supported, with none of the branches that separate excavates receiving high bootstrap support. In analyses of similar datasets with comparable models, trees in which excavates are monophyletic do not confer a significantly lower likelihood on the data than the best tree overall, with several different tests (Simpson et al., 2002c). Generally, SSU-rRNA data does not support the monophyly of Excavata, but neither does it strongly reject it (Simpson et al., 2002c).

One recent SSU-rRNA analysis (Cavalier-Smith, 2002) does find Excavata to be a monophyletic group, with strong bootstrap support $(87 \%)$. This strong support conflicts with the absence of support for excavate monophyly in the trees reported here, as well as with other recent analyses that used a variety of alignments, taxon sets and phylogenetic methods (Dacks et al., 2001; Silberman et al., 2002; Simpson et al., 2002c), and is unexplained. From a molecular perspective, the monophyly or non-monophyly of Excavata (with the taxon inclusion predicted here) remains an unanswered question. Nonetheless, SSU-rRNA trees and other molecular phylogenies do provide good evidence for close relationships between some excavate subgroups; these are detailed below.

Trimastix and oxymonads (and Malawimonas). Oxymonads, represented here by a single Pyrsonympha sequence, form a strong clade with Trimastix in SSU-rRNA trees. This relationship is recovered with various taxon inclusions and phylogenetic methods (Dacks et al., 2001) and when additional oxymonad sequences are also included (Keeling \& Leander, 2003; Moriya et al., 2003). In some SSU-rRNA trees (e.g. Fig. 6), a close relationship between Trimastix (and oxymonads) and Malawimonas is recovered, but with very weak support.

Diplomonads, retortamonads and Carpediemonas. Diplomonads and retortamonads form a strongly supported clade in SSU-rRNA trees (Fig. 6). When Giardia sequences are included, these usually form a weak clade with retortamonads (i.e. diplomonads appear to be paraphyletic). However, diplomonad monophyly is not rejected by most statistical tests (Silberman et al., 2002). Furthermore, diplomonad monophyly to the exclusion of retortamonads is supported by morphological data (see above and Fig. 5 b) and also by HSP90 protein phylogenies (unpublished data).

The diplomonad/retortamonad clade is, in turn, closely related to Carpediemonas in SSU-rRNA trees (Fig. 6). This relationship has been recovered with strong support in diverse taxon and method combinations (Simpson et al., 2002c). The same relationship is recovered with very strong support in $\alpha$-tubulin protein trees and with moderate support in $\beta$-tubulin and HSP70 trees (Simpson et al., 2002a, c).

Parabasalids. Parabasalids are often a sister to the (Carpediemonas (retortamonad, diplomonad)) clade in unrooted SSU-rRNA trees (Fig. 6), although frequently with weak support. A similar position is supported weakly by $\beta$-tubulin phylogenies (Simpson et al., 2002c) and, more strongly, by excavate-rich analyses of concatenated protein genes (unpublished data). These results are consistent with several protein analyses that place diplomonads and parabasalids as sisters when few other excavates are considered (Embley \& Hirt, 1998; Dacks \& Roger, 1999; Roger, 1999; Baldauf et al., 2000). Better excavaterich datasets are clearly required, but confirmation of the close relationship between parabasalids and the (Carpediemonas (retortamonad, diplomonad)) clade would provide strong evidence for an excavate ancestry for parabasalids, despite negligible morphological evidence.

Jakobids. Jakoba libera and Reclinomonas americana form a strong clade in SSU-rRNA trees, but Jakoba incarcerata falls separately. This separation is also seen in tubulin phylogenies, although jakobids are actually multiply polyphyletic in $\alpha$-tubulin trees (Edgcomb et al., 2001; Simpson et al., 2002c). Jakobid polyphyly is contradicted positively by morphological data (see above) and is suspected to be an artefact of phylogenetic analysis. Further study is required. The possible relationships between jakobids and other excavates are resolved poorly by SSU-rRNA data, although some protein phylogenies suggest a relationship with Euglenozoa and Heterolobosea (see below).

Euglenozoa and Heterolobosea. Heterolobosea and Euglenozoa form a clade to the exclusion of other excavates in some SSU-rRNA trees, usually with weak support (Fig. 6). A relationship between these two groups is, in fact, shown more convincingly by excavate-poor analyses of several concatenated proteins (Baldauf et al., 2000). With some more excavate-rich protein datasets (CCT $\alpha$, tubulin proteins, HSP70, HSP90 and combinations thereof), Heterolobosea and/or Euglenozoa often form weakly to moderately supported relationships with the representative jakobid Reclinomonas (Edgcomb et al., 2001; Archibald et al., 2002; unpublished data). It is possible that jakobids actually interrupt the minimal Euglenozoa-Heterolobosea clade. Thus, although the morphological case for inclusion of Euglenozoa in Excavata is negligible, existing molecular phylogenetic evidence unites Euglenozoa in a clade with the excavate taxon Heterolobosea and, possibly, with the jakobids.

The future. The striking non-monophyly of excavates in most molecular phylogenies is a serious barrier to acceptance of the excavate hypothesis and the taxon Excavata. 
It must be borne in mind, however, that there are still very few datasets with a rich sampling of excavates. Further, some excavates are already notorious for aberrant behaviour across several phylogenetic markers and might be expected to be difficult to place, even when close relatives are also included. It is anticipated that it will be very difficult to determine the true evolutionary positions of all excavates by using molecular phylogenetic approaches, at least in the near future. It is notable that some fairly well-accepted major groups that were also predicted on the basis of data other than molecular phylogenies (e.g. Plantae sensu lato and chromalveolates) are difficult to recover as robust clades in molecular phylogenies of eukaryotes.

Assuming that methodological and logistical barriers are overcome, it is predicted that all excavates identified here will eventually fall in a single clade. Presently, there is no way of excluding the possibility that one or more wellestablished groups may also form part of this clade, although there is no consistent indication from present data that this will be the case.

If the excavate hypothesis allows taxa other than currently recognized excavates to have descended from them, is it falsifiable by phylogeny? The excavate hypothesis would be falsified if one or more of the typical excavates could be demonstrated to branch within a clade where the cenancestor is already understood to be something other than a suspension-feeding, groove-bearing flagellate. For example, reliable placement of a 'typical excavate' within opisthokonts would be difficult to reconcile with the excavate hypothesis, barring lateral gene transfer. In some ways, a satisfactory examination of excavate relationships is hampered by our still-mediocre knowledge of the evolution of supposedly well-understood eukaryote groups.

\section{Classification}

As yet, there is no system of high-level phylogenetic taxonomy to describe strongly supported relationships amongst excavates. The higher-level taxa in commonest use all have circumscriptive diagnoses. Most have incurred drastic changes in concept and composition in recent years, e.g. Anaeromonada (Cavalier-Smith, 1997, 2002), Archezoa (Cavalier-Smith, 1983, 1998, 1999; Patterson, 1999), Metamonada (Grassé, 1952; Cavalier-Smith, 1981, 1998) and Percolozoa (Cavalier-Smith, 1992a, 1998, 2002). Others are explicitly paraphyletic in concept and paraphyletic or polyphyletic in fact and would be inadmissible to most systematic and evolutionary protistologists (e.g. Loukozoa; Cavalier-Smith, 1999, 2002).

\section{Recognized higher taxa}

Here, I provide a partial apomorphy-based system that recognizes some of the groups for which there is reasonable evidence from morphological data, molecular phylogenies or both (Table 2 ). The system only includes clades
Table 2. Hierarchical rankless classification of Excavata

\begin{tabular}{|l|}
\hline Taxon \\
\hline Excavata \\
Preaxostyla \\
Oxymonadida \\
Trimastix \\
Malawimonas \\
Fornicata \\
Carpediemonas \\
Eopharyngia \\
Retortamonadida \\
Diplomonadida \\
Parabasalia \\
Jakobida \\
Heterolobosea \\
Euglenozoa \\
\hline
\end{tabular}

and does not ascribe ranks to any taxon (de Queiroz \& Gauthier, 1992; Patterson, 1994). Some existing taxa for which there is reasonable evidence of monophyly, but which lack phylogenetic definitions, are also included; this includes all formal names for the basic groups of excavates, as well as Eopharyngia.

Excavata. The taxon Excavata was introduced recently by Cavalier-Smith (2002). Cavalier-Smith's diagnosis is circumscriptive, but makes no reference to the feeding groove. However, with the exception of collodictyonids, the composition of the taxon is the same as that predicted here and there is a reference to the groove in the circumscription of the presumptive stem group, 'Loukozoa'. Here, a phylogenetic diagnosis for Excavata is provided, based on the origin of the excavate feeding groove.

Fornicata. The clade that includes Carpediemonas, diplomonads and retortamonads lacks taxonomic recognition. Carpediemonas and retortamonads share an origin of the B fibre against R2, which causes the B fibre to ' $a r c h$ ' across the ventral face of the flagellar apparatus (Simpson \& Patterson, 2001). Diplomonads have secondarily lost the B fibre. The novel taxon 'Fornicata' is defined on the origin of this 'arched B fibre' (for'nix. L. masc. n. fornix arch).

Preaxostyla. The clade of Trimastix and oxymonads has no traditional name. The I fibres of these two taxa have a distinctive appearance (latticework paracrystalline layer of 'double-cross' thickness with a single, fine outer layer the I fibre in oxymonads is the paracrystalline component of the preaxostyle). The novel taxon 'Preaxostyla' is defined on the origin of this apomorphy. Cavalier-Smith (1997) erected the name Anaeromonada as an empty supertaxon for Trimastix. The diagnosis of Anaeromonada was meaningless except within a proposed systematic linkage between Trimastix and parabasalids. Cavalier-Smith 
(1999) later discarded the Trimastix-parabasalid link, but recently added oxymonads to Anaeromonada en passant and without revising the definition of the latter (CavalierSmith, 2002). Given these drastic changes in concept and content, it is considered simplest to suppress Anaeromonada and to create a novel, phylogenetically defined taxon.

Eopharyngia. In recent years, three different taxon names have been associated with the composition 'diplomonads plus retortamonads': Anaxostylaria Cavalier-Smith 1987, Eopharyngia Cavalier-Smith 1993 and Metamonada sensu Cavalier-Smith 1998. Of these, Eopharyngia is preferred here, being the most defensibly defined and consistent in conception. There is no phylogenetic definition as yet. Despite having a broadly similar organization (Brugerolle, 1991a), it is difficult to nominate unambiguous apomorphies for the clade of diplomonads and retortamonads. Interestingly, retortamonads and some diplomonads (Giardiinae and Trepomonas agilis) share the hooked appearance of R1 at its origin (Fig. 4), but further examination of the fine structure and evolutionary relationships of diplomonads is required.

\section{Phylogenetic (apomorphy-based) diagnoses of taxa}

Excavata (Cavalier-Smith 2002, emend.)

Apomorphy: suspension-feeding groove, homologous to that in Jakoba libera (Fig. 1a in Patterson, 1990).

Fornicata taxon nov.

Apomorphy: B fibre ('arched fibre') origin against R2, homologous to the organization in Chilomastix cuspidata (Fig. 4c in Bernard et al., 1997).

Preaxostyla taxon nov.

Apomorphy: I fibre with preaxostylar substructure (doublecross matrix, with a single fine outer sheet), homologous to that in Pyrsonympha vertens (Fig. 6 in Brugerolle, 1970).

\section{Acknowledgements}

Thanks to David (Paddy) J. Patterson, Andrew J. Roger, Charles J. O’Kelly, Joel B. Dacks, Sarah L. Poynton, Serguei Karpov, Patrick J. Keeling and an anonymous reviewer for valuable discussions and/or comments. A. G. B. S. was supported by a Canadian Institutes of Health Research (CIHR) postdoctoral fellowship and a scholar appointment by the Canadian Institute for Advanced Research (CIAR).

\section{References}

Archibald, J. M., O'Kelly, C. J. \& Doolittle, W. F. (2002). The chaperonin genes of jakobid and jakobid-like flagellates: implications for eukaryotic evolution. Mol Biol Evol 19, 422-431.
Balamuth, W., Bradbury, P. C. \& Schuster, F. L. (1983). Ultrastructure of the amoeboflagellate Tetramitus rostratus. J Protozool 30, 445-455.

Baldauf, S. L., Roger, A. J., Wenk-Siefert, I. \& Doolittle, W. F. (2000). A kingdom-level phylogeny of eukaryotes based on combined protein data. Science 290, 972-977.

Bernard, C., Simpson, A. G. B. \& Patterson, D. J. (1997). An ultrastructural study of a free-living retortamonad, Chilomastix cuspidata (Larsen and Patterson, 1990) n. comb. (Retortamonadida, Protista). Eur J Protistol 33, 254-265.

Bernard, C., Simpson, A. G. B. \& Patterson, D. J. (2000). Some free-living flagellates (Protista) from anoxic habitats. Ophelia 52, 113-142.

Broers, C. A. M., Stumm, C. K., Vogels, G. D. \& Brugerolle, G. (1990). Psalteriomonas lanterna gen. nov., sp. nov., a free-living amoeboflagellate isolated from freshwater anaerobic sediments. Eur J Protistol 25, 369-380.

Broers, C. A. M., Meijers, H. H. M., Symens, J. C., Stumm, C. K., Vogels, G. D. \& Brugerolle, G. (1993). Symbiotic association of Psalteriomonas vulgaris n. spec. with Methanobacterium formicicum. Eur J Protistol 29, 98-105.

Brugerolle, G. (1970). Sur l'ultrastructure et la position systématique de Pyrsonympha vertens (Zooflagellata, Pyrsonymphina). $C R$ Acad Sci (Paris) 270, 966-969 (in French).

Brugerolle, G. (1973). Etude ultrastructurale du trophozoite et du kyste chez le genre Chilomastix Aléxéieff, 1910 (Zoomastigophorea, Retortamonadida Grassé, 1952). J Protozool 20, 574-585 (in French).

Brugerolle, G. (1975a). Etude ultrastructurale du genre Enteromonas da Fonseca (Zoomastigophorea) et révision de l'ordre des Diplomonadida Wenyon. J Protozool 22, 468-475 (in French).

Brugerolle, G. (1975b). Contribution a l'étude cytologique et phylétique des diplozoaires (Zoomastigophorea, Diplozoa, Dangeard 1910). V. Nouvelle interprétation de l'organisation cellulaire de Giardia. Protistologica 11, 99-109 (in French).

Brugerolle, G. (1975c). Contribution a l'étude cytologique et phylétique des diplozoaires (Zoomastigophorea, Diplozoa, Dangeard 1910). VI. Caractères généraux des diplozoaires. Protistologica 11, 111-118 (in French).

Brugerolle, G. (1977). Ultrastructure du genre Retortamonas Grassi 1879 (Zoomastigophorea, Retortamonadida Wenrich 1931). Protistologica 13, 233-240 (in French).

Brugerolle, G. (1991a). Flagellar and cytoskeletal systems in amitochondrial flagellates: Archamoeba, Metamonada and Parabasala. Protoplasma 164, 70-90.

Brugerolle, G. (1991b). Cell organization in free-living amitochondriate heterotrophic flagellates. In The Biology of Free-Living Heterotrophic Flagellates, pp. 133-148. Edited by D. J. Patterson and J. Larsen. Oxford: Clarendon Press.

Brugerolle, G. (1992). Flagellar apparatus duplication and partition, flagellar transformation during division in Entosiphon sulcatum. Biosystems 28, 203-209.

Brugerolle, G. \& Taylor, F. J. R. (1977). Taxonomy, cytology and evolution of the Mastigophora. In Proceedings of the 5th International Congress of Protozoology, pp. 14-28. Edited by S. H. Hutner. New York: Society of Protozoologists.

Brugerolle, G. \& Patterson, D. J. (1997). Ultrastructure of Trimastix convexa Hollande, an amitochondriate anaerobic flagellate with a previously undescribed organisation. Eur J Protistol 33, 121-130.

Brugerolle, G. \& Lee, J. J. (2000a). Order Oxymonadida. In The Illustrated Guide to the Protozoa, 2nd edn, pp. 1186-1195. Edited by J. J. Lee, G. F. Leedale and P. Bradbury. Lawrence, KS: Society of Protozoologists. 
Brugerolle, G. \& Lee, J. J. (2000b). Phylum Parabasalia. In The Illustrated Guide to the Protozoa, 2nd edn, pp. 1196-1249. Edited by J. J. Lee, G. F. Leedale and P. Bradbury. Lawrence, KS: Society of Protozoologists.

Brugerolle, G. \& Müller, M. (2000). Amitochondriate flagellates. In Flagellates: Unity, Diversity and Evolution, pp. 166-189. Edited by J. C. Green and B. S. C. Leadbeater. London: Taylor \& Francis.

Brugerolle, G. \& Regnault, J.-P. (2001). Ultrastructure of the enteromonad flagellate Caviomonas mobilis. Parasitol Res 87, 662-665.

Brugerolle, G., Joyon, L. \& Öktem, N. (1973a). Contribution a l'étude cytologique et phylétique des diplozoaires (Zoomastigophorea, Diplozoa Dangeard 1910). I. Étude ultrastructurale du genre Trepomonas (Dujardin). Protistologica 9, 339-348 (in French).

Brugerolle, G., Joyon, L. \& Öktem, N. (1973b). Contribution a l'étude cytologique et phylétique des diplozoaires (Zoomastigophorea, Diplozoa Dangeard 1910). II. Étude ultrastructurale du genre Spironucleus (Lavier 1936). Protistologica 9, 495-502 (in French).

Brugerolle, G., Joyon, L. \& Öktem, N. (1974). Contribution a l'étude cytologique et phylétique des diplozoaires (Zoomastigophorea, Diplozoa Dangeard 1910). IV. Étude ultrastructurale du genre Octomitus (Prowazek 1904). Protistologica 10, 457-463 (in French).

Brugerolle, G., Kunstyr, I., Senaud, J. \& Friedhoff, K. T. (1980). Fine structure of trophozoites and cysts of the pathogenic diplomonad Spironucleus muris. Z Parasitenkd 62, 47-61.

Brugerolle, G., Bricheux, G., Philippe, H. \& Coffe, G. (2002). Collodictyon triciliatum and Diphylleia rotans (=Aulacomonas submarina) form a new family of flagellates (Collodictyonidae) with tubular mitochondrial cristae that is phylogenetically distant from other flagellate groups. Protist 153, 59-70.

Cavalier-Smith, T. (1981). Eukaryote kingdoms: seven or nine? Biosystems 14, 461-481.

Cavalier-Smith, T. (1983). A 6-kingdom classification and a unified phylogeny. In Endocytobiology II, pp. 1027-1034. Edited by W. Schwemmler and H. E. A. Schenk. Berlin: Walter de Gruyter.

Cavalier-Smith, T. (1987). Eukaryotes with no mitochondria. Nature 326, 332-333.

Cavalier-Smith, T. (1991). Cell diversification in heterotrophic flagellates. In The Biology of Free-Living Heterotrophic Flagellates, pp. 113-131. Edited by D. J. Patterson and J. Larsen. Oxford: Clarendon Press.

Cavalier-Smith, T. (1992a). Percolozoa and the symbiotic origin of the metakaryote cell. In Endocytobiology V, pp. 399-406. Edited by S. Sato, M. Ishida and H. Ishikawa. Tübingen, Germany: Tübingen University Press.

Cavalier-Smith, T. (1992b). Origin of the cytoskeleton. In The Origin and Evolution of the Cell, pp. 79-106. Edited by H. Hartman and K. Matsumo. Singapore: World Scientific.

Cavalier-Smith, T. (1993). Kingdom Protozoa and its 18 phyla. Microbiol Rev 57, 953-994.

Cavalier-Smith, T. (1997). Amoeboflagellates and mitochondrial cristae in eukaryote evolution: megasystematics of the new protozoan subkingdoms Eozoa and Neozoa. Arch Protistenkd 147, 237-258.

Cavalier-Smith, T. (1998). A revised six-kingdom system of life. Biol Rev Camb Philos Soc 73, 203-266.

Cavalier-Smith, T. (1999). Principles of protein and lipid targeting in secondary symbiogenesis: euglenoid, dinoflagellate, and sporozoan plastid origins and the eukaryote family tree. J Eukaryot Microbiol 46, 347-366.

Cavalier-Smith, T. (2000). Flagellate megaevolution: the basis for eukaryote diversification. In The Flagellates: Unity, Diversity and Evolution, pp. 361-390. Edited by J. C. Green and B. S. C. Leadbeater. London: Taylor \& Francis.
Cavalier-Smith, T. (2002). The phagotrophic origin of eukaryotes and phylogenetic classification of Protozoa. Int J Syst Evol Microbiol 52, 297-354.

Corliss, J. O. (1994). An interim utilitarian ("user-friendly") hierarchical classification and characterization of the Protists. Acta Protozool 33, 1-51.

Dacks, J. \& Roger, A. J. (1999). The first sexual lineage and the relevance of facultative sex. J Mol Evol 48, 779-783.

Dacks, J. B., Silberman, J. D., Simpson, A. G. B., Moriya, S., Kudo, T., Ohkuma, M. \& Redfield, R. (2001). Oxymonads are closely related to the excavate taxon Trimastix. Mol Biol Evol 18, 1034-1044.

de Queiroz, K. \& Gauthier, J. (1992). Phylogenetic taxonomy. Аnnu Rev Ecol Syst 23, 449-480.

Desser, S. S., Hong, H., Siddall, M. E. \& Barta, J. R. (1993). An ultrastructural study of Brugerolleia algonquinensis gen. nov., sp. nov. (Diplomonadida; Diplomonadina), a flagellate parasite from the blood of frogs from Ontario, Canada. Eur J Protistol 29, 72-80.

Edgcomb, V. P., Roger, A. J., Simpson, A. G. B., Kysela, D. T. \& Sogin, M. L. (2001). Evolutionary relationships among "jakobid" flagellates as indicated by alpha- and beta-tubulin phylogenies. Mol Biol Evol 18, 514-522.

Embley, T. M. \& Hirt, R. P. (1998). Early branching eukaryotes? Curr Opin Genet Dev 8, 624-629.

Eriksson, T. (1999). AUTODECAY 4.0. Bergius Foundation, Royal Swedish Academy of Sciences, Stockholm, Sweden.

Eyden, B. P. \& Vickerman, K. (1975). Ultrastructure and vacuolar movements in the free-living diplomonad Trepomonas agilis Klebs. J Protozool 22, 54-66.

Farmer, M. A. \& Triemer, R. E. (1988). Flagellar systems in the euglenoid flagellates. Biosystems 21, 283-291.

Fenchel, T. \& Patterson, D. J. (1986). Percolomonas cosmopolitus (Ruinen) n. gen., a new type of filter feeding flagellate from marine plankton. J Mar Biol Assoc U K 66, 465-482.

Fenchel, T. \& Finlay, B. J. (1995). Ecology and Evolution in Anoxic Worlds. Oxford: Oxford University Press.

Flavin, M. \& Nerad, T. A. (1993). Reclinomonas americana n. g., n. sp., a new freshwater heterotrophic flagellate. J Eukaryot Microbiol 40, 172-179.

Friend, D. S. (1966). The fine structure of Giardia muris. J Cell Biol 29, 317-332.

Grassé, P.-P. (1952). Classe des Zooflagellés: Zooflagellata ou Zoomastigina. In Traité de Zoologie, vol. 1, fasc. 1, pp. 963-982. Edited by P.-P. Grassé. Paris: Masson (in French).

Hinkle, G. \& Sogin, M. L. (1993). The evolution of the Vahlkampfiidae as deduced from 16S-like ribosomal RNA analysis. J Eukaryot Microbiol 40, 599-603.

Hirt, R. P., Logsdon, J. M., Jr, Healy, B., Dorey, M. W., Doolittle, W. F. \& Embley, T. M. (1999). Microsporidia are related to fungi: evidence from the largest subunit of RNA polymerase II and other proteins. Proc Natl Acad Sci U S A 96, 580-585.

Holberton, D. V. (1973). Fine structure of the ventral disk apparatus and the mechanism of attachment in the flagellate Giardia muris. $J$ Cell Sci 13, 11-41.

Horner, D. S. \& Embley, T. M. (2001). Chaperonin 60 phylogeny provides further evidence for secondary loss of mitochondria among putative early-branching eukaryotes. Mol Biol Evol 18, 1970-1975.

Keeling, P. J. \& Doolittle, W. F. (1997). Widespread and ancient distribution of a noncanonical genetic code in diplomonads. Mol Biol Evol 14, 895-901. 
Keeling, P. J. \& Leander, B. S. (2003). Characterisation of a noncanonical genetic code in the oxymonad Streblomastix strix. J Mol Biol 326, 1337-1349.

Kulda, J., \& Nohynková, E. (1978). Flagellates of the human intestine and of intestines of other species. In Parasitic Protozoa, vol. 2, pp. 1-138. Edited by J. P. Kreier. New York: Academic Press.

Leander, B. S. \& Keeling, P. J. (2003). Morphostasis in alveolate evolution. Trends Ecol Evol 18, 395-402.

Leander, B. S., Triemer, R. E. \& Farmer, M. A. (2001). Character evolution in heterotrophic euglenids. Eur J Protistol 37, 337-356.

Lipscomb, D. L. (1989). Relationships among the eukaryotes. In The Hierarchy of Life, pp. 161-178. Edited by B. Fernholm, K. Bremer and H. Jörnvall. Amsterdam: Elsevier.

Mignot, J. P. \& Brugerolle, G. (1975). Etude ultrastructurale du flagelle phagotrophe Colponema loxodes Stein. Protistologica 11, 429-444 (in French).

Moestrup, $\varnothing$. (2000). The flagellate cytoskeleton: introduction of a general terminology for microtubular flagellar roots in protists. In The Flagellates: Unity, Diversity and Evolution. Edited by J. C. Green and B. S. C. Leadbeater. London: Taylor \& Francis.

Moriya, S., Dacks, J. B., Takagi, A., Noda, S., Ohkuma, M., Doolittle, W. F. \& Kudo, T. (2003). Molecular phylogeny of three oxymonad genera: Pyrsonympha, Dinenympha and Oxymonas. J Eukaryot Microbiol 50, 190-197.

Morrison, H. G., Roger, A. J., Nystul, T. G., Gillin, F. D. \& Sogin, M. L. (2001). Giardia lamblia expresses a proteobacterial-like DnaK homolog. Mol Biol Evol 18, 530-541.

Mylnikov, A. P. (1989). The fine structure and systematic position of Histiona aroides (Bicoecales). Bot Zh 74, 184-189 (in Russian).

Mylnikov, A. P. (1991). Diversity of flagellates without mitochondria. In The Biology of Free-Living Heterotrophic Flagellates, pp. 149-158. Edited by D. J. Patterson and J. Larsen. Oxford: Clarendon Press.

Nielsen, M. H., Ludvik, J. \& Nielsen, R. (1966). On the ultrastructure of Trichomonas vaginalis Donné. J Microsc (Paris) 5, 229-250.

O'Kelly, C. J. (1993). The jakobid flagellates: structural features of Jakoba, Reclinomonas and Histiona and implications for the early diversification of eukaryotes. J Eukaryot Microbiol 40, 627-636.

O'Kelly, C. J. (1997). Ultrastructure of trophozoites, zoospores and cysts of Reclinomonas americana Flavin \& Nerad, 1993 (Protista incertae sedis: Histionidae). Eur J Protistol 33, 337-348.

O’Kelly, C. J. \& Nerad, T. A. (1999). Malawimonas jakobiformis n. gen., n. sp. (Malawimonadidae fam. nov.): a Jakoba-like heterotrophic nanoflagellate with discoidal mitochondrial cristae. J Eukaryot Microbiol 46, 522-531.

O’Kelly, C. J., Farmer, M. A. \& Nerad, T. A. (1999). Ultrastructure of Trimastix pyriformis (Klebs) Bernard et al.: similarities of Trimastix species with retortamonad and jakobid flagellates. Protist 150, 149-162.

Page, F. C. \& Blanton, R. L. (1985). The Heterolobosea (Sarcodina: Rhizopoda), a new class uniting the Schizopyrenida and the Acrasidae (Acrasida). Protistologica 21, 121-132.

Patterson, D. J. (1988). The evolution of protozoa. Mem Inst Oswaldo Cruz 83 (Suppl. 1), 580-600.

Patterson, D. J. (1990). Jakoba libera (Ruinen, 1938), a heterotrophic flagellate from deep oceanic sediments. J Mar Biol Assoc U K 70, 381-393.

Patterson, D. J. (1994). Protozoa: evolution and systematics. In Progress in Protozoology, pp. 1-14. Edited by K. Hausmann and N. Hülsmann. Berlin: Gustav Fischer Verlag.

Patterson, D. J. (1999). The diversity of eukaryotes. Am Nat 154 (Suppl.), S96-S124.
Patterson, D. J. \& Zölffel, M. (1991). Heterotrophic flagellates of uncertain taxonomic position. In The Biology of Free-Living Heterotrophic Flagellates, pp. 427-475. Edited by D. J. Patterson and J. Larsen. Oxford: Clarendon Press.

Patterson, D. J., Rogerson, A. \& Vørs, N. (2000a). Class Heterolobosea. In The Illustrated Guide to the Protozoa, 2nd edn, pp. 1104-1111. Edited by J. J. Lee, G. F. Leedale and P. Bradbury. Lawrence, KS: Society of Protozoologists.

Patterson, D. J., Vørs, N., Simpson, A. G. B. \& O'Kelly, C. J. (2000b) Residual free-living and predatory heterotrophic flagellates. In The Illustrated Guide to the Protozoa, 2nd edn, pp. 1302-1328. Edited by J. J. Lee, G. F. Leedale and P. Bradbury. Lawrence, KS: Society of Protozoologists.

Philippe, H. \& Adoutte, A. (1998). The molecular phylogeny of Eukaryota: solid facts and uncertainties. In Evolutionary Relationships Among Protozoa, pp. 25-56. Edited by G. H. Coombs, K. Vickerman, M. A. Sleigh and A. Warren. London: Chapman \& Hall.

Philippe, H., Lopez, P., Brinkmann, H., Budin, K., Germot, A. Laurent, J., Moreira, D., Müller, M. \& Le Guyader, H. (2000). Earlybranching or fast-evolving eukaryotes? An answer based on slowly evolving positions. Proc R Soc Lond B Biol Sci 267, 1213-1221.

Radek, R. (1994). Monocercomonoides termitis n. sp., an oxymonad from the lower termite Kalotermes sinaicus. Arch Protistenkd 144, 373-382.

Roger, A. J. (1999). Reconstructing early events in eukaryotic evolution. Am Nat 154 (Suppl.), S146-S163.

Roger, A. J., Svärd, S. G., Tovar, J., Clark, C. G., Smith, M. W., Gillin, F. D. \& Sogin, M. L. (1998). A mitochondrial-like chaperonin 60 gene in Giardia lamblia: evidence that diplomonads once harbored an endosymbiont related to the progenitor of mitochondria. Proc Natl Acad Sci U S A 95, 229-234.

Ruinen, J. (1938). Notizen uber Salzflagellaten. II. Uber die Verbreitung der Salzflagellaten. Arch Protistenkd 90, 210-258 (in German).

Siddall, M. E., Hong, H. \& Desser, S. S. (1992). Phylogenetic analysis of the Diplomonadida (Wenyon, 1926) Brugerolle, 1975: evidence for heterochrony in protozoa and against Giardia lamblia as a "missing link". J Protozool 39, 361-367.

Silberman, J. D., Simpson, A. G. B., Kulda, J., Cepicka, I., Hampl, V., Johnson, P. J. \& Roger, A. J. (2002). Retortamonad flagellates are closely related to diplomonads - implications for the history of mitochondrial function in eukaryote evolution. Mol Biol Evol 19, 777-786.

Simpson, A. G. B. (1997). The identity and composition of the Euglenozoa. Arch Protistenkd 148, 318-328.

Simpson, A. G. B. \& Patterson, D. J. (1999). The ultrastructure of Carpediemonas membranifera (Eukaryota), with reference to the excavate hypothesis. Eur J Protistol 35, 353-370.

Simpson, A. G. B. \& Patterson, D. J. (2001). On core jakobids and excavate taxa: the ultrastructure of Jakoba incarcerata. J Eukaryot Microbiol 48, 480-492.

Simpson, A. G. B., van den Hoff, J., Bernard, C., Burton, H. R. \& Patterson, D. J. (1997). The ultrastructure and systematic position of the euglenozoon Postgaardi mariagerensis, Fenchel et al. Arch Protistenkd 147, 213-225.

Simpson, A. G. B., Bernard, C. \& Patterson, D. J. (2000). The ultrastructure of Trimastix marina Kent, 1880 (Eukaryota), an excavate flagellate. Eur J Protistol 36, 229-252.

Simpson, A. G. B., MacQuarrie, E. K. \& Roger, A. J. (2002a). Early origin of canonical introns. Nature 419, 270.

Simpson, A. G. B., Radek, R., Dacks, J. B. \& O'Kelly, C. J. (2002b). How oxymonads lost their groove: an ultrastructural comparison of 
Monocercomonoides and excavate taxa. J Eukaryot Microbiol 49, 239-248.

Simpson, A. G. B., Roger, A. J., Silberman, J. D., Leipe, D. D., Edgcomb, V. P., Jermiin, L. S., Patterson, D. J. \& Sogin, M. L. (2002c). Evolutionary history of 'early diverging' eukaryotes: the excavate taxon Carpediemonas is a close relative of Giardia. Mol Biol Evol 19, 1782-1791.

Sleigh, M. A. (1988). Flagellar root maps allow speculative comparisons of root patterns and of their ontogeny. Biosystems 21, 277-282.

Sleigh, M. A. (1989). Protozoa and other Protists. London: Edward Arnold.

Sogin, M. L. (1989). Evolution of eukaryotic microorganisms and their small subunit ribosomal RNAs. Am Zool 29, 487-499.

Sterud, E., Mo, T. A. \& Poppe, T. T. (1997). Ultrastructure of Spironucleus barkhanus n. sp. (Diplomonadida: Hexamitidae) from grayling Thymallus thymallus (L.) (Salmonidae) and Atlantic salmon Salmo salar L. (Salmonidae). J Eukaryot Microbiol 44, 399-407.

Stiller, J. W. \& Hall, B. D. (1999). Long-branch attraction and the rDNA model of early eukaryotic evolution. Mol Biol Evol 16, 1270-1279.

Swofford, D. L. (2000). PAUP*: Phylogenetic Analysis Using Parsimony (*and other methods), version 4. Sunderland, MA: Sinauer Associates.

Tachezy, J., Sánchez, L. B. \& Müller, M. (2001). Mitochondrial type iron-sulfur cluster assembly in the amitochondriate eukaryotes Trichomonas vaginalis and Giardia intestinalis, as indicated by the phylogeny of IscS. Mol Biol Evol 18, 1919-1928.

Tovar, J., Leon-Avila, G., Sánchez, L. B., Sutak, R., Tachezy, J., van der Geizen, M., Hernández, M., Müller, M. \& Lucocq, J. M. (2003). Mitochondrial remnant organelles of Giardia function in iron-sulphur cluster metabolism. Nature (in press). 